\title{
Comparative transcriptomics identifies the
}

transcription factors BRANCHED1 and TCP4, as well as the microRNA miR166 as candidate genes

involved in the evolutionary transition from dehiscent to indehiscent fruits in Lepidium

\section{Lydia Gramzow}

Friedrich Schiller University Jena

Katharina Klupsch

Friedrich Schiller University Jena

Noé Fernández Pozo

University of Marburg

Martin Hölzer

Friedrich Schiller University Jena

Manja Marz

Friedrich Schiller University Jena

Stefan A. Rensing

University of Marburg

Günter Theißen ( $\sim$ guenter.theissen@uni-jena.de )

Friedrich Schiller University Jena

\section{Research Article}

Keywords: transcriptome, fruit development, dehiscence, differentially expressed genes, Lepidium appelianum, Lepidium campestre

Posted Date: November 2nd, 2021

DOI: https://doi.org/10.21203/rs.3.rs-1031457/v1

License: (c) (1) This work is licensed under a Creative Commons Attribution 4.0 International License.

Read Full License 
1 Comparative transcriptomics identifies the transcription factors BRANCHED1 and

2 TCP4, as well as the microRNA miR166 as candidate genes involved in the

3 evolutionary transition from dehiscent to indehiscent fruits in Lepidium

4 (Brassicaceae)

5

6 Lydia Gramzow ${ }^{1}$, Katharina Klupsch ${ }^{1}$, Noé Fernández Pozo ${ }^{2}$, Martin Hölzer ${ }^{3 \dagger}$, Manja Marz ${ }^{3}$,

7 Stefan A. Rensing ${ }^{2,4}$ and Günter Theißen ${ }^{1 *}$

8

$9{ }^{1}$ Matthias Schleiden Institute / Genetics, Friedrich Schiller University Jena, 07743 Jena,

10 Germany

11 2Plant Cell Biology, Department of Biology, University of Marburg, 35043 Marburg, Germany

${ }^{3}$ RNA Bioinformatics and High-Throughput Analysis, Friedrich Schiller University Jena, 07743

13 Jena, Germany

$14{ }^{4}$ Centre for Biological Signaling Studies (BIOSS), University of Freiburg, 79108 Freiburg,

15 Germany

16

$17{ }^{\dagger}$ Current address: Methodology and Research Infrastructure, Bioinformatics, Robert Koch

18 Institute, 13353 Berlin, Germany

19 *Corresponding author: Günter Theißen, guenter.theissen@uni-jena.de

20

21 Keywords: transcriptome, fruit development, dehiscence, differentially expressed genes,

22 Lepidium appelianum, Lepidium campestre

23

24 
Abstract

Background: Fruits are the seed-bearing structures of flowering plants and are highly diverse in terms of morphology, texture and maturation. Dehiscent fruits split open upon maturation to discharge their seeds while indehiscent fruits are dispersed as a whole. Indehiscent fruits evolved from dehiscent fruits several times independently in the crucifer family (Brassicaceae). The fruits of Lepidium appelianum, for example, are indehiscent while the fruits of the closely related L. campestre are dehiscent. Here, we investigate the molecular and genetic mechanisms underlying the evolutionary transition from dehiscent to indehiscent fruits using these two Lepidium species as model system.

Results: We have sequenced the transcriptomes and small RNAs of floral buds, flowers and fruits of $L$. appelianum and $L$. campestre and analyzed differentially expressed genes (DEGs) and differently differentially expressed genes (DDEGs). DEGs are genes that show significantly different transcript levels in the same structures (buds, flowers and fruits) in different species, or in different structures in the same species. DDEGs are genes for which the change in expression level between two structures is significantly different in one species than in the other. Comparing the two species, the highest number of DEGs was found in flowers, followed by fruits and floral buds while the highest number of DDEGs was found in fruits versus flowers followed by flowers versus floral buds. Several gene ontology terms microRNA miR166 as well as the TCP transcription factors BRANCHED1 (BRC1) and TCP FAMILY TRANSCRIPTION FACTOR 4 (TCP4) were found to be DDEGs.

Conclusions: Our study reveals differences in gene expression between dehiscent and indehiscent fruits and uncovers miR166, BRC1 and TCP4 as possible causes for the evolutionary transition from dehiscent to indehiscent fruits in Lepidium. 


\section{Background}

53 Flowering plants (angiosperms) form fruits to protect and disperse their seeds. Fruits come in many different types with different morphologies and different properties such as dry or fleshy, and dehiscent or indehiscent (Lorts and Briggeman 2008). There is a tremendous variation in fruit types both across and within different plant lineages (Dardick and Callahan 2014). However, the evolutionary mechanisms that enabled such dramatic shifts to occur, often in a relatively short period of time, remain largely unknown.

The crucifer family (Brassicaceae) includes a number of economically important plants such as cabbage, broccoli, mustard, radish, and turnips. The model plant Arabidopsis thaliana is also a member of this family (Initiative 2000). Typical fruits of Brassicaceae species are dehiscent, i.e. that the fruits open upon maturation to release the seeds. Dehiscent fruits also likely represents the ancestral fruit type of Brassicaceae (Hall et al. 2002). However, indehiscent fruits, i.e. fruits that only release the seed upon decomposition of the fruit, are found in many tribes distributed across the Brassicaceae phylogeny (Appel et al. 2003). The scattered distribution of indehiscent fruits indicates that this property evolved independently several times. This situation is mirrored in the genus Lepidium belonging to Brassicaceae: Species of this genus typically produce two-seeded dehiscent fruits, but the genus also includes species with indehiscent fruits (Al-Shehbaz and Mummenhoff 2011). Brassicaceae fruits are composed of two fruit valves that are connected to the replum and enclose the developing seeds. Dehiscent fruits, such as those of $A$. thaliana and Lepidium campestre (also known as field pepperwort or field cress), form a well-defined dehiscence zone (DZ) at the valve margin (Mühlhausen et al. 2013). The DZ consists of the lignified layer, a stripe of lignified cells, and a separation layer, a region of small thin-walled cells (Spence et al. 1996; Rajani and Sundaresan 2001). During fruit ripening, the whole fruit dries and shrinks. Only the lignified structures stay rigid. Thereby a spring-like tension is created within the fruit. At the same time, the middle lamellae of the separation layer cells degenerate to form a predetermined breaking zone at which the pressure tears the valves apart from the replum. Consequently, the fruit bursts open to release the seeds (Meakin and Roberts 1990, 1991; 
Spence et al. 1996). In contrast, the indehiscent fruits of the closely related Lepidium appelianum do not form a DZ. Instead, a continuous ring of lignified cells surrounds the seeds such that the fruit cannot open (Mühlhausen et al. 2013).

Much of the gene regulatory network underlying the proper formation of the fruit valves, replum and DZ has been elucidated in A. thaliana (reviewed in (Ballester and Ferrándiz 2017)). Establishment of the DZ requires expression of the two redundant MADS box genes, SHATTERPROOF1 (SHP1) and SHATTERPROOF2 (SHP2). The SHP1 and SHP2 proteins act as transcription factors and activate the basic helix-loop-helix protein-encoding genes INDEHISCENT (IND), ALCATRAZ (ALC) and SPATULA (SPT), and also autonomously contribute to DZ development (Liljegren et al. 2000; Liljegren et al. 2004; Rajani and Sundaresan 2001; Groszmann et al. 2011).

For correct fruit patterning, it is crucial that the expression of the SHP genes is restricted to the DZ. Three transcription factors contribute to this process: The MADS box gene FRUITFULL (FUL) which is expressed in the fruit valves (Gu et al. 1998; Ferrandiz et al. 2000), the BEL1like homeobox gene REPLUMLESS (RPL) (Roeder et al. 2003), also known as PENNYWISE (Smith and Hake 2003), BELLRINGER (Byrne et al. 2003), VAAMANA (Bhatt et al. 2004), and BLH9 (Cole et al. 2006) which is expressed in the replum, and the floral homeotic gene APETALA2 (AP2) which also negatively regulates RPL (Ripoll et al. 2011).

Transcription factors controlling the expression of these negative regulators have also been determined. High levels of the $\mathrm{C} 2 \mathrm{H} 2$ zinc finger proteins JAGGED (JAG) and the two closely related YABBY1 group proteins FILAMENTOUS FLOWER (FIL) and YABBY3 (YAB3) activate the expression of FUL (Dinneny et al. 2005). In contrast, lower levels of JAG/FIL/YAB3 expression promote expression of SHP genes. The expression of RPL is activated by the knotted1-like homeobox protein BREVIPEDICELLUS (BP) (Alonso-Cantabrana et al. 2007) whose gene is in turn activated by the $\mathrm{C} 2 \mathrm{H} 2$ zinc finger protein NO TRANSMITTING TRACT (NTT) (Marsch-Martínez et al. 2014). AP2 is negatively regulated be the microRNA miR172 (Ripoll et al. 2015). 
Additionally, other factors which influence the size and the position of the DZ have been identified. The WUSCHEL-RELATED HOMEOBOX gene 13 (WOX13) controls replum width and negatively regulates JAG/FIL/YAB3 (Romera-Branchat et al. 2013). The auxin-response factors ARF6 and ARF8, which are regulated by miR167 (Zheng et al. 2019), activate miR172 together with FUL (Ripoll et al. 2015). The MYB protein ASYMMETRIC LEAVES 1 (AS1), likely in collaboration with the leucine zipper protein ASYMMETRIC LEAVES 2 (AS2), negatively regulates BP (Alonso-Cantabrana et al. 2007).

In general, proteins encoded by genes expressed in the replum often negatively regulate genes expressed in the valves and vice versa. Apart from the already mentioned interactions, this includes negative regulation of the replum gene $B P$ by the valve proteins encoded by $J A G / F I L / Y A B 3$, and negative regulation of JAG/FIL/YAB3 by the replum protein RPL (González-Reig et al. 2012).

In a previous study, we have shown that orthologues of the valve margin genes are expressed in a similar way in L. campestre (dehiscent fruits) as in A. thaliana fruits but that expression of the respective orthologues is abolished in the corresponding tissues of indehiscent Lepidium appelianum fruits (Mühlhausen et al. 2013). As parallel mutations in different genes are unlikely, we concluded that the changes in gene expression patterns are probably caused by changes in upstream regulators such as FUL, RPL or AP2.

To conduct a more unbiased approach to identify the genetic changes that lead from dehiscent to indehiscent fruits than the analysis of candidate genes, we have sequenced the transcriptomes of floral buds, flowers and fruits of both, L. campestre and L. appelianum in the present study. We have identified differentially expressed genes (DEGs) and differently differentially regulated genes (DDEGs) where the latter refers to genes for which the change in expression level between two structures is significantly different in one species than in the other. More DEGs were identified in flowers than in fruits and floral buds and a higher number of DDEGs was found in fruits versus flowers than in flowers versus floral buds. Cell wall synthesis and degradation are important processes for fruit opening as revealed by gene ontology (GO) analysis. The fruit valve identity genes FRUITFUL and YABBY3 were identified 
as DEGs such that the possible cause for the evolutionary transition from dehiscent to indehiscent fruits in Lepidium may even be an upstream factor of these genes. Possible candidates are BRANCHED1 (BRC1), an ortholog of which may determine whether dehiscent or indehiscent fruit develop on the dimorphic plant Aethionema arabicum, and TCP FAMILY TRANSCRIPTION FACTOR 4 (TCP4) which may regulate YABBY3. These two genes were found to be DDEGs. Our study elucidates differences in gene expression patterns between dehiscent and indehiscent fruits and reveals BRC1 and TCP4 as possible causes for the evolutionary transition from dehiscent to indehiscent fruits in Lepidium.

\section{Results}

\section{Overview of the RNA-seq analysis and transcriptome assembly}

Sequencing resulted in an average number of reads per library of 56 Mio. for the mRNA and 12 Mio. for the small RNA (Table 1). An initial analysis of the data revealed contamination with sequences from thrips, likely due to infestation of the plants by these animals. Hence, we removed reads matching to the genome of the thrips Frankliniella occidentalis (González et al. 2018) as well as uncorrectable and unpaired reads and reads corresponding to organelle sequences. After this filtering step, 42 Mio. were retained for further analyses for the mRNA sample. For the small RNA sample many reads seem to be derived from organelle RNA. Hence, after removing uncorrectable reads and those matching to the Frankliniella occidentalis genome and organelle sequences, only 1.5 Mio. reads remained on average for the small RNA sample (Table 1).

Assembly using Trinity (Grabherr et al. 2011a) resulted in a total of 56,413 transcripts for $L$. campestre and 70,380 transcripts for $L$. appelianum after removing putative contaminant sequences but including potential splice variants or fragmentary sequences. The assemblies also contained chimeric sequences composed of two different transcripts which were likely a result of mis-assembly (Yang and Smith 2013b). Separation of chimeric sequences increased

161 the number of transcripts to a total of 57,209 for $L$. campestre and 71,332 for L. appelianum. We used the Benchmarking Universal Single-Copy Orthologs (BUSCO) tool (Simão et al. 
2015) with the dataset eudicotyledons_odb10 as reference to assess completeness of our transcriptomes. The BUSCO analyses revealed that $94.6 \%$ of the expected eudicotyledonous "near-universal single-copy orthologs" are present in our assembly of the L. campestre transcriptome while $94.3 \%$ of these BUSCOs are present in our L. appelianum transcriptome (Figure 1). It is common that some genes are fragmented in de novo assemblies. Hence, we analyzed the length distribution of our assemblies. For both species there are two peaks (Figure 2). One peak appears at a length of about 240 nucleotides and probably represents fragments. The other peak was found at a length of about 1,450 nucleotides which indicates that there are also a number of full-length transcripts.

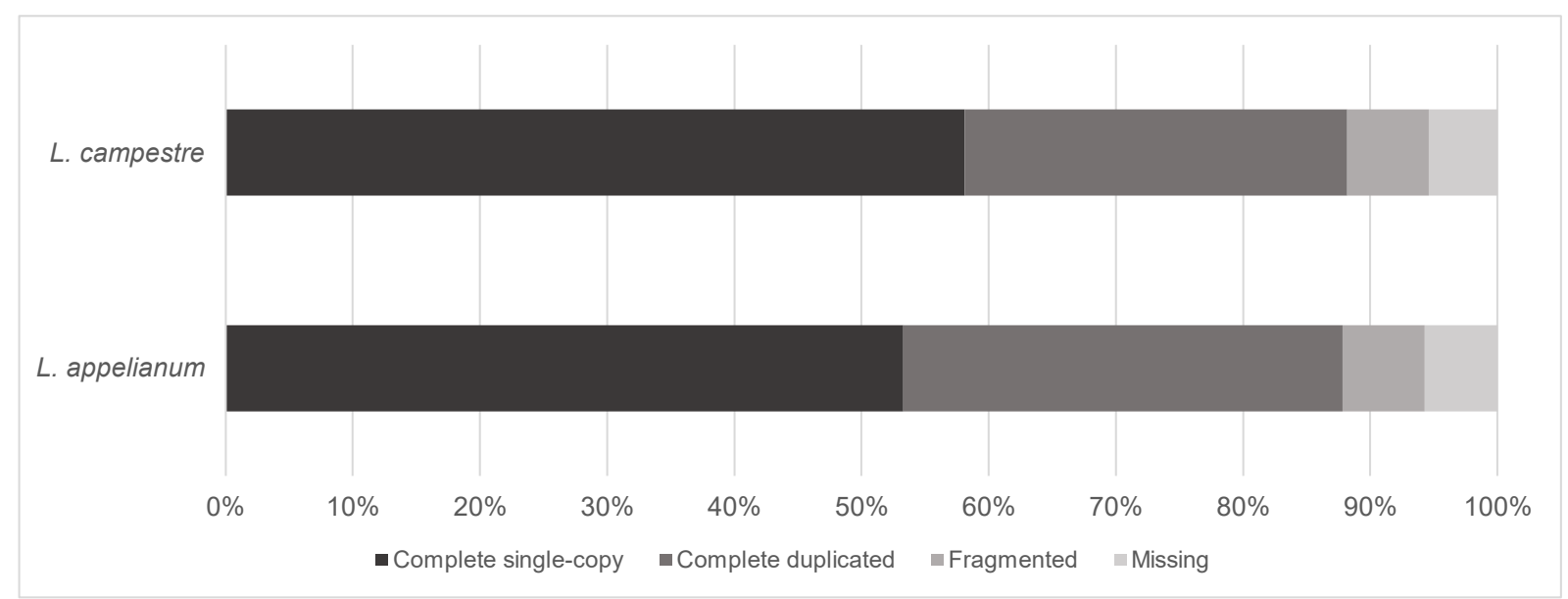

Figure 1: BUSCO completeness analysis. Transcripts from the $L$. campestre and $L$. appelianum assemblies were compared to 2121 Eudicotyledons reference orthologs for completeness assessment.

To detect conserved miRNAs, we mapped the small RNA reads onto the mature miRNAs of A. thaliana as provided by miRBase (Kozomara et al. 2019a). We found reads for 64 mature miRNAs belonging to 32 miRNA families in the L. campestre small RNA data (Table 2). Using ShortStack (Axtell 2013) and the L. campestre genome as available from NCBI, we identified three novel miRNAs. However, no putative target genes could be identified in the transcriptome of $L$. campestre using targetfinder (https://github.com/carringtonlab/TargetFinder). Our $L$. appelianum small RNA data contained reads of 60 mature miRNAs belonging to 30 miRNA families (Table 2). No novel miRNAs could be identified for $L$. appelianum using ShortStack and our transcriptome as reference "genome". 


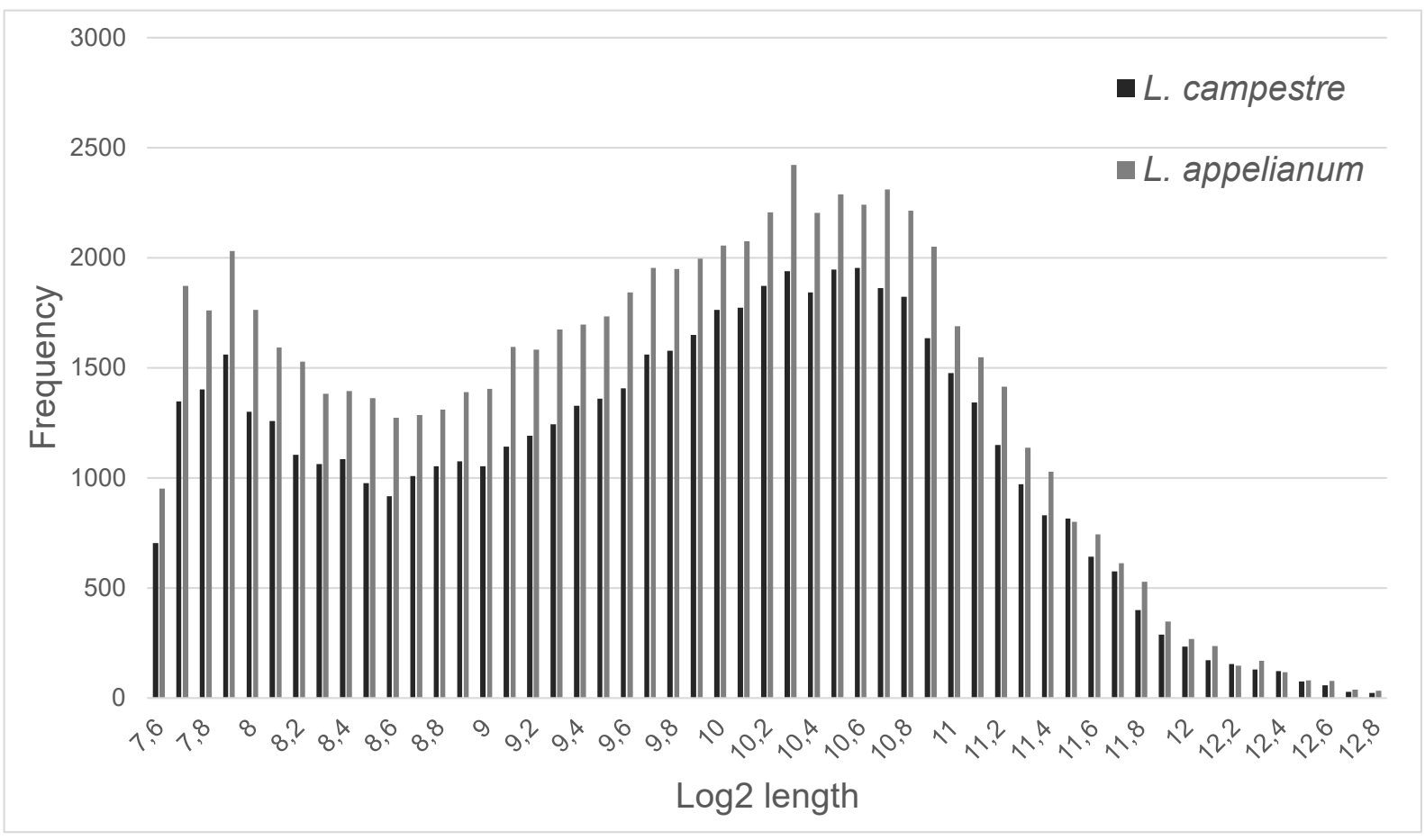

Figure 2: Transcript length distribution of the assembled transcripts of $L$. campestre and $L$. appelianum.

To assess completeness of our small RNA data, we compared our results to the set of conserved and moderately conserved miRNA families as identified by miRNA sample sequencing of vascular plants (Montes et al. 2014). For both species, we identified reads for all 16 miRNA families that were found to have originated before the emergence of eudicots and to be conserved across virtually all corresponding species. Furthermore, we found reads for 6 miRNA families in our $L$. campestre and 7 miRNA families in our $L$. appelianum small RNA data out of 21 miRNA families which were classified as conserved, although missing in a few corresponding species.

Differential gene expression analysis

To conduct differential expression and regulation analysis, we identified putative ortholog pairs between the transcripts of the two Lepidium species as described in the methods section. We

201 attained two transcriptome datasets, one for $L$. campestre and one for $L$. appelianum, each containing 17,755 transcripts and where each transcript in one species has exactly one 
putative orthologous transcript in the other species. We will refer to these transcriptome

204

205

206

207

208

209

210

211

212

213

214

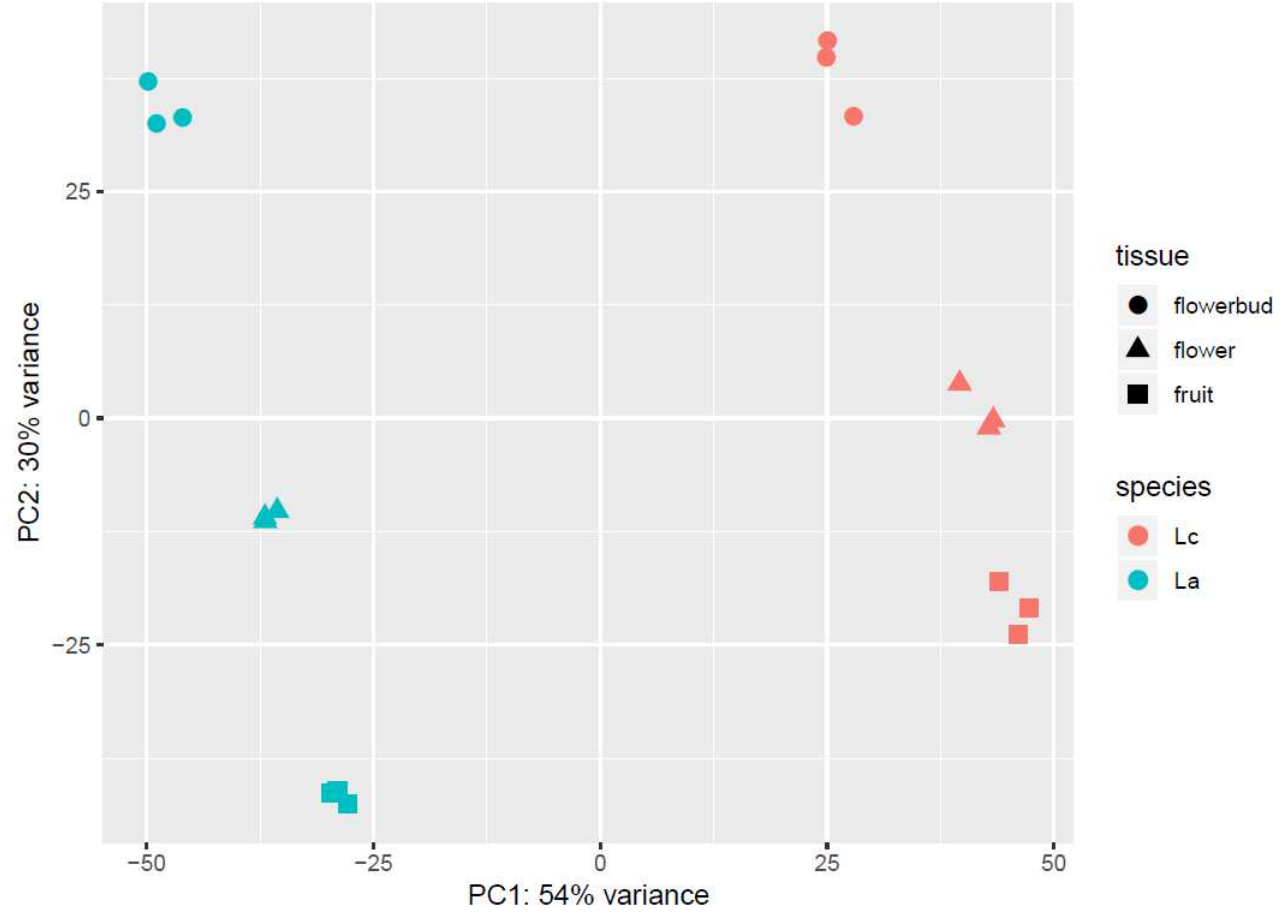

216 Figure 3: Principal component analysis of gene expression profiles of all samples. Samples

217 from L. campestre are shown in red, samples from L. appelianum are shown in blue. Samples from

218 floral buds are depicted by circles, samples from flowers by triangles and samples from fruits by

219 squares. PCA shows separation of the two species and the different structures. 
221 To learn more about the differences in fruit development between the $L$. campestre and $L$. 222 appelianum, we analyzed expression in our ortholog-transcriptomes using the programs 223 DESeq2 (Love et al. 2014a) and edgeR (Robinson et al. 2010a). We used a multi-factor design 224 to not only be able to identify differentially expressed genes (DEGs) between the species in 225 the same structure and between structures in the same species, but also to identify genes 226 where the change in expression between the structures is different between the two species. 227 We will refer to the genes identified in the latter analyses as differently differentially expressed 228 genes (DDEGs).

229 DESeq2 generally identified more DEGs and DDEGs than edgeR, but there is a great overlap 230 of genes identified by both programs (Figure 4). Only this overlap between the two methods 231 will be considered in the following. More DEGs were observed between the same structure of 232 the different species as compared to different structures of the same species. In L. campestre, 233 there are similar numbers of DEGs between flower and bud as compared to fruit and flower. 234 In L. appelianum, there are more than twice as many DEGs in flowers versus buds as 235 compared to fruits versus flowers (Figure 4). When looking at DEGs in the same structure of 236 the different species, the highest number of DEGs in observed in flowers, followed by fruits 237 and buds.

238 We also analyzed DDEGs in our dataset, i.e. genes which had a significantly different change 239 in expression in flowers versus buds and in fruits versus flowers, respectively, in L. appelianum 240 as compared to L. campestre. These genes may have a significantly stronger up- or 241 downregulation in L. appelianum as compared to $L$. campestre or these genes may be 242 downregulated in one species and upregulated in the other species. We found 70 DDEGs in 243 flowers versus buds and 158 DDEGs in fruits versus flowers when comparing the two species 244 (Figure 4). 
Lepidium campestre
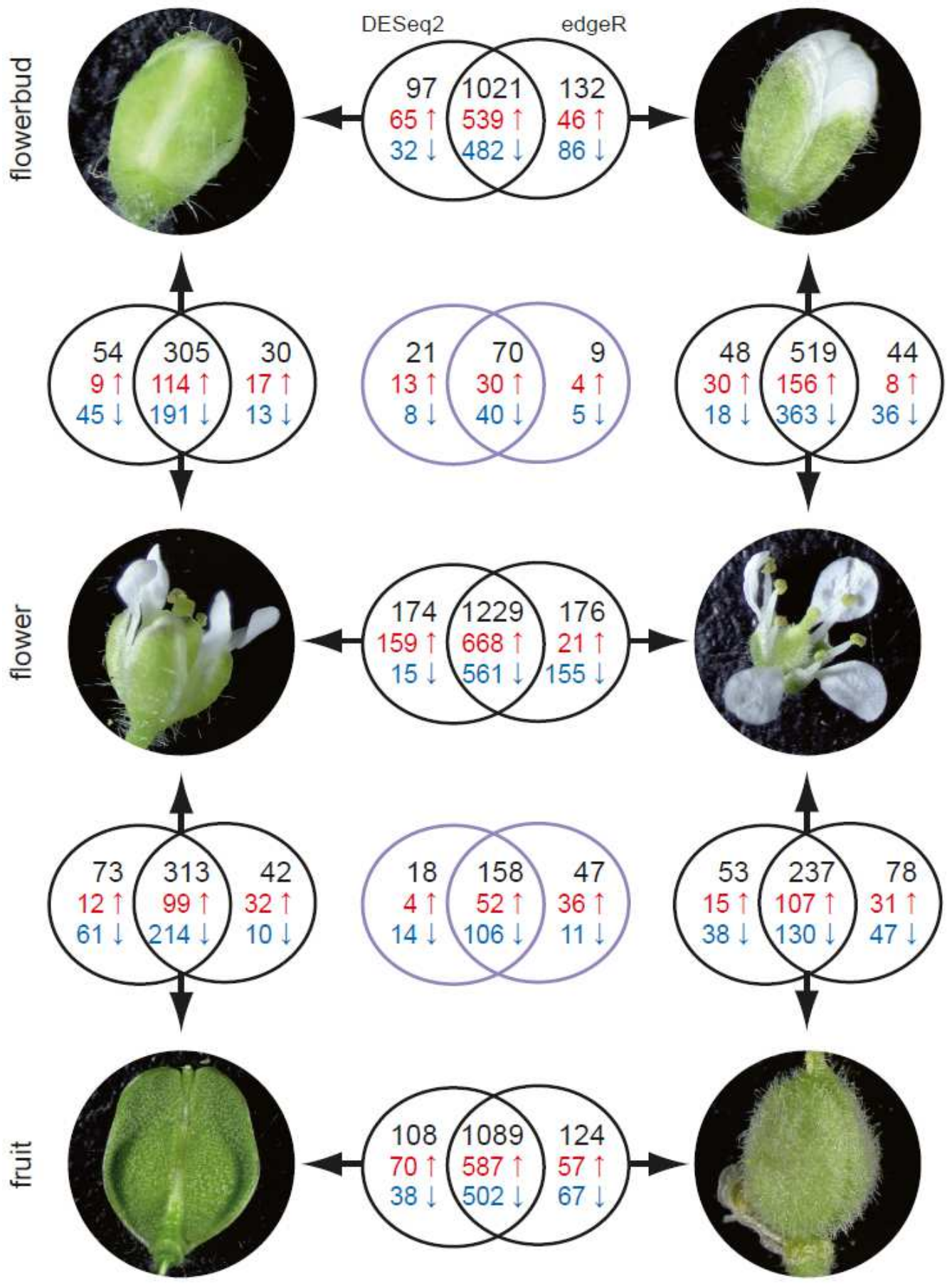

Figure 4: Venn diagrams of the DEGs and DDEGs between different species and different

structures. The DEGs and DDEGs were called by the two programs edgeR and DESeq2. Venn diagrams between floral buds, flowers and fruits, respectively, of $L$. campestre and $L$. appelianum represent differentially expressed genes (DEGs) between the two species in the corresponding structure. Venn diagrams between different structures of the same species represent DEGs between those structures in the corresponding species. The two lavender Venn diagramms indicate differently differentially expressed genes (DDEGs) between flower and floral buds and between fruits and flowers, 
respectively, when comparing the two species. Black numbers in the Venn diagram correspond to all DEGs or DDEGs while red numbers represent up- and blue numbers represent downregulated genes.

We applied the same methods for the identification of DEGs and DDEGs encoding miRNAs. First, we determined orthologs between the miRNAs based on the A. thaliana miRNAs they mapped to. For 56 mature miRNAs belonging to 28 miRNA families reads were found in the small RNA data for both species and these mature miRNAs could thus be used for differential expression analyses (Table 2). We will refer to this dataset as our ortholog-miRNAs. All 16 miRNA families that are conserved across virtually all species according to (Montes et al. 2014) and 6 out of 21 miRNA families which were classified as moderately conserved belong to our ortholog-miRNAs dataset. Mapping of small RNA reads, counting and differential expression analyses were done as described for the differential expression analysis of the orthologtranscriptomes.

Only one miRNA was found to be encoded by a DEG or DDEG by both programs DESeq2 and edgeR. The miRNA homologous to miR165a-3p, miR165b, miR166a-3p, miR166b-3p, miR166c, miR166d, miR166e-3p, miR166f and miR166g of Arabidopsis thaliana (Reinhart et al. 2002) (they all only differ by one nucleotide), which we will refer to as miR165a-3p, was found to be encoded by a DDEG when comparing fruits and flowers. Targets of miR165 and miR166 are HD-Zip transcription factors like PHABULOSA, REVOLUTA and PHAVOLUTA (Rhoades et al. 2002).

\section{Gene Ontology and transcription factor analyses}

A number of gene ontology (GO) terms (Ashburner et al. 2000; Gene Ontology Consortium 2021) of the category molecular function are significantly over- or underrepresented in the DEGs and DDEGs (Table 3). Among them, the terms protein binding (GO:0005515) and RNA binding (GO:0003723) were underrepresented in two datasets of DEGs. Interestingly, several GO terms related to cell wall synthesis and degradation, i.e. pectinesterase activity (GO:0030599), cellulose synthase (UDP-forming) activity (GO:0016760), polygalacturonase 
activity (GO:0004650) and hydrolase activity, hydrolyzing O-glycosyl compounds

282 (GO:0004553) were overrepresented in different sets of DEGs.

283 As we were interested in differences in the gene regulatory network involved in fruit dehiscence 284 in the two species, known to be largely composed of transcription factors in Arabidopsis 285 thaliana (reviewed in (Ballester and Ferrándiz 2017)), we analyzed genes annotated to have 286 "DNA-binding transcription factor activity" (GO:0003700) in more detail. This set includes 287 transcription factors and transcriptional regulators. For simplicity, we will refer to this dataset 288 as genes encoding transcription factors (TFs).

289 When comparing flowers and buds, 21 and 28 TFs were DEGs in L. campestre and in $L$. 290 appelianum, respectively. Among them, there are 13 TFs that were DEGs comparing these 291 structures in both species, including four genes with known functions in flower development AGAMOUS-LIKE 104 (AGL104) (Adamczyk and Fernandez 2009), SPOROCYTELESS (SPL, also termed NOZZLE) (Balasubramanian and Schneitz 2000), ORESARA1 (ORE1, also termed ANAC092, ATNAC2, ATNAC6) (Gao et al. 2018) and ZINC FINGER PROTEIN 2 (ZFP2) (Cai and Lashbrook 2008) (Table 4). Between fruits and flowers, there are 12 TFs in

L. campestre and 23 TFs in L. appelianum that are DEGs. Five of these genes are DEGs in 297 fruits versus flowers in both species (Table 4). TFs with differential expression between 298 structures in both species are probably those TFs with common functions for flower and fruit 299 development.

300 When comparing the two species, 43 TFs were DEGs in buds, 68 in flowers and 49 in fruits. 301 Among these TFs, 19 were DEGs in all structures (Table 5). Interestingly, four genes involved 302 in flowering time determination, SQUAMOSA PROMOTER BINDING PROTEIN-LIKE 4 (SPL4) 303 (Jung et al. 2016), NUCLEAR FACTOR Y-B2 (NF-YB2) (Cao et al. 2014), NUCLEAR FACTOR 304 Y-B10 (NF-YB10) (Wenkel et al. 2006) and FLOWERING LOCUS C (FLC) (Michaels and 305 Amasino 1999), as well as the fruit development genes FRUITFUL (FUL) (Gu et al. 1998) and 306 YABBY3 (YAB3) (Dinneny et al. 2005; González-Reig et al. 2012) (Figure 5) were on this list. 


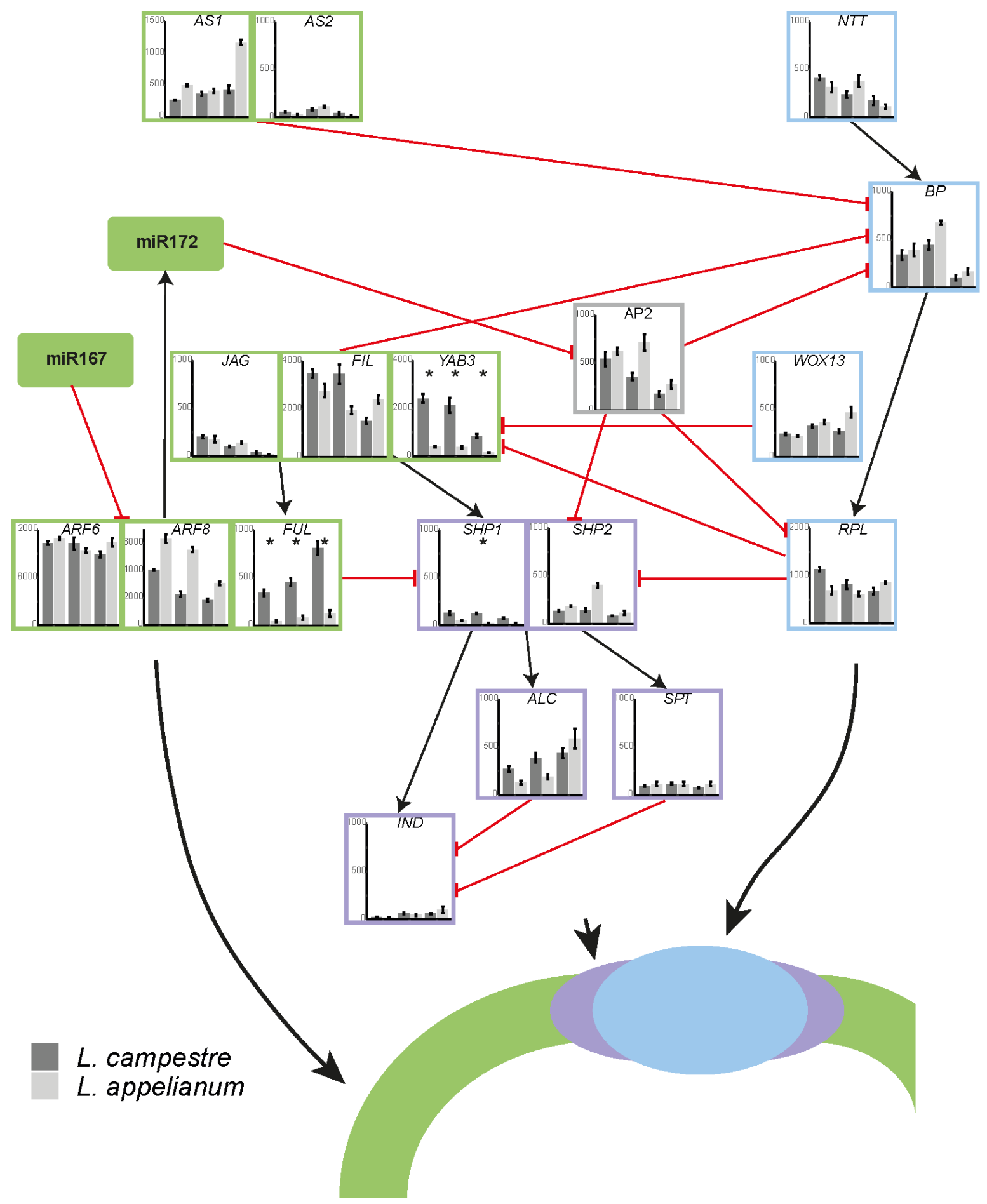

309 Figure 5: Gene regulatory network for the development of valve, valve margin and replum of a fruit. The network is based on what has been determined in A. thaliana and is modified after Chavez-

311 Montez et al., 2015. Relative expression levels of genes in L. campestre and L. appelianum as 
determined in this study by transcriptome analysis are shown. Significant differences between $L$. appelianum and L. campestre are indicated by asterisks $(P \leq 0.05)$.

Two TFs were found to be DDEGs when comparing flowers and buds in the two species (Table 6), among them MASSUGU 2 (MSG2, also known as INDOLE-3-ACETIC ACID INDUCIBLE 19) (Tatematsu et al. 2004) which has been shown to be involved in stamen filaments development (Tashiro et al. 2009). Comparing fruits and flowers, seven TFs, PHYINTERACTING FACTOR 1 (PIF1, also known as PHYTOCHROME INTERACTING FACTOR 3-LIKE 5) (Huq et al. 2004), MYB DOMAIN PROTEIN 57 (MYB57) (Bender et al. 2013), TCP FAMILY TRANSCRIPTION FACTOR 4 (TCP4, also known as MATERNAL EFFECT EMBRYO ARREST 35) (Nag et al. 2009), BRANCHED 1 (BRC1, also known as TCP FAMILY TRANSCRIPTION FACTOR 18) (Aguilar-Martínez et al. 2007), REVEILLE 6 (RVE6) (Hsu et al. 2013), TRIPTYCHON (TRY) (Schnittger et al. 1999) and OBF BINDING PROTEIN 4 (OBP4, also termed DOF5.4) (Xu et al. 2016) are DDEGs in L. appelianum as compared to $L$. campestre.

\section{Extension of the gene regulatory network for fruit development}

We next investigated how the TFs shown to be differentially regulated between fruits and flowers may be involved in the gene regulatory network controlling fruit development (Figure 5). Therefore, we searched for binding sites of the seven TFs identified by chromatin immunoprecipitation followed by sequencing (ChIP-seq) experiments in the promotors of the genes known to be involved in fruit development. On ChIP-Hub (Chen et al. 2019), no ChIPseq data is available for BRC1 and for TRY.

Binding of OBP4 was found in the promotor of all but one of the 18 fruit development genes (Table 7). Binding of RVE6, MYB57, PIF1 and TCP4 was detected in the promotors of 11, 7, 5 and 2 fruit development genes, respectively. PIF1 predominantly binds to the promotors of valve identity genes, with binding to four out of eight valve identity gene promotors and apart from that only binding to one of five valve margin genes. ARF8 is the only fruit development gene for which none of the differentially regulated genes was found to bind to its promotor. To 
340 the promotors of $Y A B 3$ and FUL, which were found to be differentially expressed in all 341 structures between $L$. campestre and $L$. appelianum, binding of TCP4, RVE6 and OBP4 and 342 of MYB57, RVE6 and OBP4, respectively, was found.

Discussion

345 Transcriptomes and small RNA datasets of $L$. campestre and $L$. appelianum are nearly 346 complete

347 We have sequenced the transcriptomes of floral buds, flowers and fruits of L. campestre and 348 L. appelianum. Benchmarking of Universal Single-Copy Orthologs (BUSCO) analysis revealed 349 that the transcriptome assemblies of the two species contain more than $94 \%$ of the eudicotyledonous "near-universal single-copy orthologs". This number is similar to or more than that for transcriptome assemblies of other Brassicaceae (Chandler et al. 2020; Yao et al. 2020; Fernandez-Pozo et al. 2021). Furthermore, we found members of all 16 miRNA families that were found to have originated before the emergence of eudicots and conserved in eudicots (Montes et al. 2014). These findings reveal that our transcriptome and small RNA data includes most of the expected transcripts and miRNAs.

\section{Differences in gene expression mainly between floral structures}

357 We identified more DEGs when comparing the same structure between the two species than 358 comparing different structures in the same species (Figure 4). This indicates that gene 359 regulation has diverged between the two species. This is different to what has been observed other flowering plant species, where the correlation of gene expression is higher in the same structure of different species than in different structures of the same species (Chanderbali et al. 2010). However, in this case microarray expression data was analyzed which may select for conserved genes and structures at similar developmental time points were compared.

364 The highest number of DEGs was observed in flowers, followed by fruits and buds, and the 365 highest number of DDEGs was found in fruits versus flowers as compared to flowers versus 366 floral buds. This indicates that the differences in gene expression between L. campestre and 367 L. appelianum are most pronounced between flowers and in the transition from flowers to fruits. 
This is expected as the developmental program leading to fruit dehiscence or indehiscence

needs to be initiated before the fruits are formed. Supportingly, in Aethionema arabicum, a plant that develops dehiscent and indehiscent fruits on the very same individual, differences between the fruit types start to occur in flowers after anthesis (Lenser et al. 2018).

A number of GO terms related to cell wall synthesis and degradation, e.g. pectinesterase activity, cellulose synthase activity and polygalacturonase activity were overrepresented in different sets of DEGs. It has been recognized that secondary cell wall formation at the valve margins (Mitsuda and Ohme-Takagi 2008) and degeneration of cell walls in the separation layer are essential processes for fruit dehiscence after the DZ is correctly specified (Ogawa et al. 2009). Hence, the overrepresentation of GO terms related to cell wall synthesis and degradation is not surprising.

\section{Confirmation of previous expression study}

380 In a previous study, we have compared expression of the valve margin genes as well as the 381 valve gene FUL and the replum gene RPL between $L$. campestre and $L$. appelianum by in situ hybridization (Mühlhausen et al. 2013). We showed that their orthologues from L. campestre (dehiscent fruits) are similarly expressed as in $A$. thaliana while expression of the respective orthologues is abolished in valve margins of indehiscent $L$. appelianum fruits. Analysis using qRT-PCR revealed that the valve margin genes IND and SHP1 are expressed at a significantly higher level in flowers and early fruits (the fruit stage for which the transcriptome was sequenced here) of $L$. campestre than in $L$. appelianum. Significantly higher expression was confirmed in the present study for SHP1 in flowers (Figure 5). qRT-PCR analysis revealed significantly higher expression of SHP2 in flowers and of $A L C$ in early fruits in $L$. appelianum. Expression was not significantly different in the present transcriptome analysis, but expression was also found to be higher for SHP2 in flowers and for ALC in fruits. Like qRT-PCR analysis, our transcriptome analysis also found significantly higher expression of $F U L$ in fruits of $L$. 393 campestre. Similarly, $R P L$ was found to be expressed at a higher level in the flowers of $L$. 394 campestre though the difference was only found to be significant in qRT-PCR but not in transcriptome analysis. AP2 was found to be expressed at a lower level in flowers and fruits of 
L. campestre by both analyses. Again, the difference was significant in qRT-PCR analysis but not in transcriptome analysis. Hence, our transcriptome analysis is in good agreement with the previous qRT-PCR analyses, but differences were less often significant.

\section{Known flower and fruit development genes are differentially expressed}

401 To identify differences in the regulation of flower and fruit development between L. campestre 402 and L. appelianum, we focused on differentially expressed or differentially differentially

403 404 expressed transcription factors (TFs). Among 19 TFs which were found to be differentially expressed in all three examined structures, four TFs are involved in flowering time determination. L. appelianum and L. campestre have different flowering periods according to the Jepson Herbarium (Jepson Flora Project (eds.) 2021, Jepson eFlora, https://ucjeps.berkeley.edu/eflora/, accessed on May 25, 2021), which may be caused by differences in the expression of the identified flowering time genes.

As mentioned above, the fruit development genes SHP1 and FUL were found to be differentially expressed. FUL expressed at a significantly lower level in $L$. appelianum in all three structures. In $A$. thaliana, the ful knockout mutation causes indehiscence in (Gu et al. 1998; Ferrandiz et al. 2000). Furthermore, YAB3 (Dinneny et al. 2005; González-Reig et al. 2012) (Figure 5) was also differentially expressed in floral buds, flowers and fruits. FUL is activated by JAG, FIL and YAB3 (Dinneny et al. 2005). Concordantly, we found that YAB3 has a significant higher expression level in L. campestre than in L. appelianum. Expression of JAG and $F I L$ is not significantly different between both species. yab3 single mutants do not have any major defects in dehiscence but fil yab3 double mutants are largely indehiscent (Dinneny et al. 2005). Hence, decreased expression of $Y A B 3$ in $L$. appelianum as compared to $L$. campestre may have been an important factor for the evolutionary shift from dehiscent to indehiscent fruits in L. appelianum. This also shows that there was not only a change in the control of valve margin identity genes but also of the valve identity genes and shifts the causative mutation further upstream in the gene regulatory network of fruit development. 


\section{MiR166 is differentially regulated in fruits versus flowers}

425 Our smallRNA sequencing revealed that the miRNA homologous to miR165a-3p, miR165b, miR166a-3p, miR166b-3p, miR166c, miR166d, miR166e-3p, miR166f and miR166g (Reinhart et al. 2002) is encoded by a DDEG when comparing fruits and flowers. Targets of miR 165 and miR166 are the mRNAs of HD-Zip transcription factors like PHABULOSA (PHB), REVOLUTA and PHAVOLUTA (Rhoades et al. 2002). Recently, a function of the miR166-PHB module in anther dehiscence has been elucidated (Li et al. 2019). Upregulation of miR166 in the jba-1D mutant leads to downregulation of its target gene PHB which results in increased expression of SPOROCYTELESS/NOZZLE (SPL/NZZ). jba-1D mutants do not develop a dehiscence zone in anthers, i.e. overexpression of miR166 leads to indehiscence of anthers. Expression

434 of miR166 in fruits is much higher in L. appelianum (indehiscent fruits) than in L. campestre 435 (dehiscent fruits), while the opposite is the case in flowers (Figure 6). Hence, miR166 may 436 have a role in the development of indehiscent fruits in L. appelianum though the details of the 437 regulation remain to be elucidated.

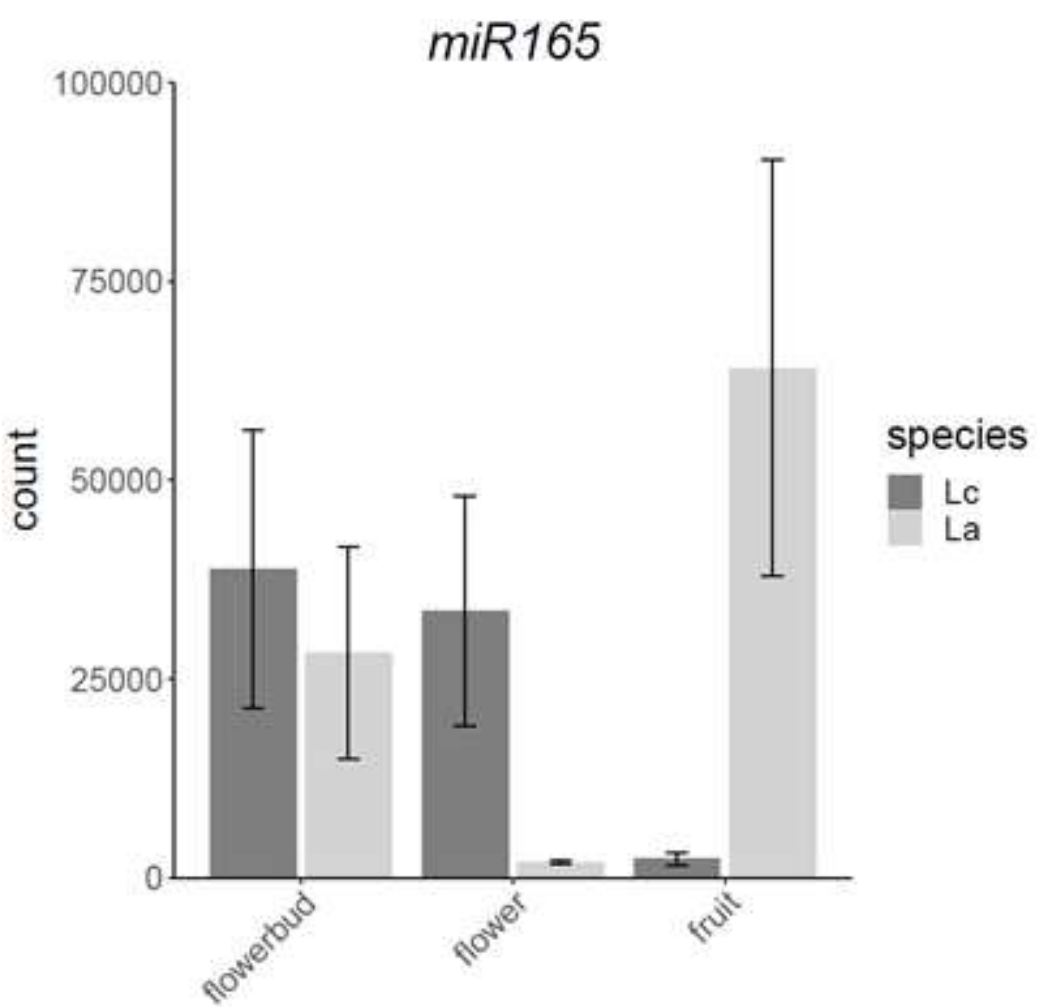

Figure 6: Expression data plot of the miRNA homologous to miR165a-3p of $A$. thaliana. miR165a$3 p$ is identical to miR165b, miR166a-3p, miR166b-3p, miR166c, miR166d, miR166e-3p, miR166f and miR166g such that they cannot be distinguished and hence are summarized here as miR165. Bars 
indicate mean normalized count values of reads mapping to miR165 in the corresponding structure and species. Dark and light grey bars represent the mean values for $L$. campestre (Lc) and for $L$. appelianum (La), respectively. The error bars indicate the standard deviation.

\section{BRC1 and TCP4 as candidate genes for the evolutionary shift from dehiscent to}

\section{indehiscent fruits}

Our transcriptome analysis also identified seven TFs belonging to DDEGs when comparing flowers and fruits (Table 6). PIF1 is a basic helix-loop-helix (bHLH) transcription factor that negatively regulates chlorophyll biosynthesis (Huq et al. 2004); it is involved in a variety of biological processes such as the repression of light-induced seed germination and chlorophyll accumulation in light (Castillon et al. 2007). RVE6 is a MYB gene that controls the pace of the circadian clock together with its close homologs RVE4 and RVE8 (Hsu et al. 2013). The zinc finger gene OBP4 functions in cell cycle progression and cell expansion (Xu et al. 2016) and is involved in root development (Rymen et al. 2017; Ramirez-Parra et al. 2017). So far, involvement of these three factors in flower and fruit development has, to the best of our knowledge, not been reported.

Two other MYB genes, MYB57 and TRY have also been found to be differentially regulated (Table 6). MYB57 functions redundantly with MYB21 and MYB24 to regulate stamen development (Cheng et al. 2009). TRY controls the spacing pattern of trichomes, which are single-celled hairs (Schnittger et al. 1999). Recently it has been found that TRY and other MYB genes of the regulatory network for trichome patterning have been modulated to trigger trichome development in fruits (Arteaga et al. 2021). Hence, these two gene are known to function during flower and fruit development but association with fruit dehiscence is not known so far.

More interestingly, the genes encoding for the two TCP transcription factors BRC1 and TCP4 are DDEGs between fruits and flowers when comparing $L$. campestre and $L$. appelianum. Expression of BRC1 correlates with bud inhibition (Aguilar-Martínez et al. 2007; Braun et al. 2012) but recently, it has been shown that $B R C 1$ is neither necessary nor sufficient for bud 
470 inhibition (Seale et al. 2017). Noticeably, it has been hypothesized that BRC1 may guide fruit

471 morph determination in the dimorphic Brassicaceae plant Aethionema arabicum (Lenser et al.

472 2018). Ae. arabicum produces two fruit morphs on the same plant, one of which is dehiscent 473 and the other one is indehiscent. qRT-PCR analyses showed that the expression of $B R C 1$ in 474 Ae. arabicum is high in flowers and decreases strongly in the indehiscent morph but remains 475 at a low level in flowers and fruits of the dehiscent morph. We observe a very similar pattern 476 in our transcriptome analysis for the indehiscent morph in L. appelianum and the dehiscent 477 morph in L. campestre (Figure 7). It is not known, however, as to how BRC1 interacts with the 478 genes of the fruit development network (Figure 5).

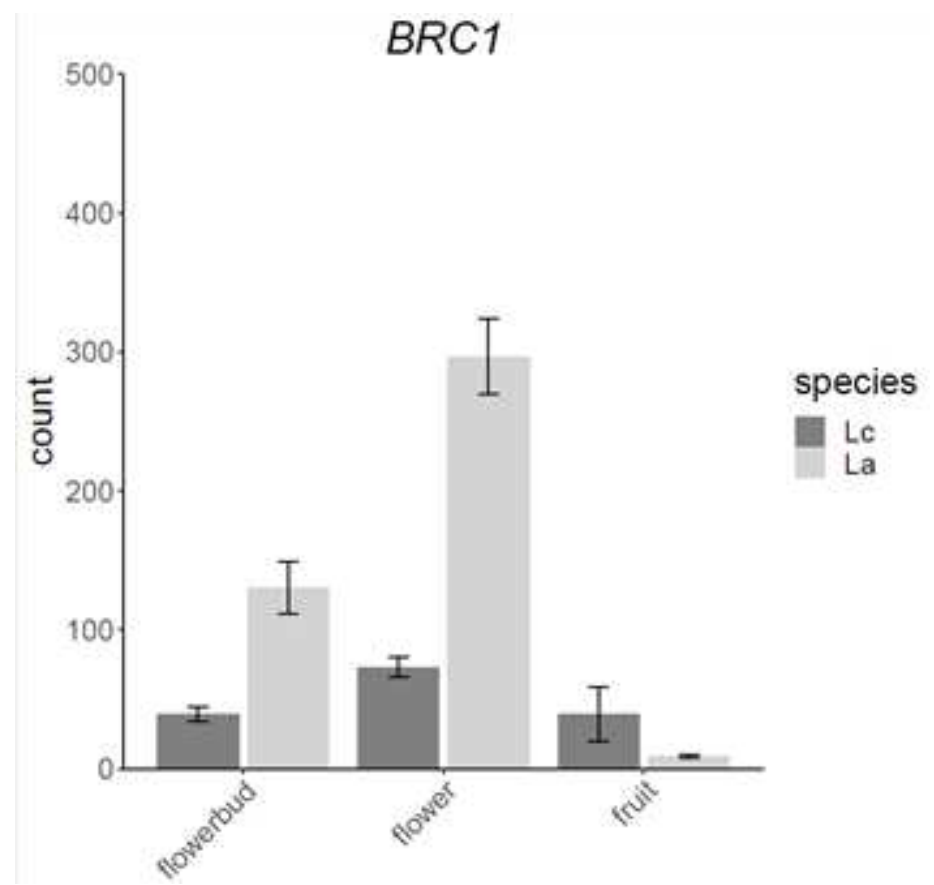

Figure 7: Expression data plot of BRC1 in L. campestre (LC) and L. appelianum (La). Bars indicate mean normalized count values of reads mapping to $B R C 1$ in the corresponding structure and species. Dark and light grey bars represent the mean values for L. campestre (Lc) and for L. appelianum (La), respectively. The error bars indicate the standard deviation.

484

TCP4 has been found to be involved in leaf and flower development as well as in seed oil biosynthesis in $A$. thaliana (Kong et al. 2020; Nag et al. 2009; Palatnik et al. 2003). 487 Furthermore, TCP4 directly activates the expression of miR167 which targets the TFs ARF6 and ARF8 (Rubio-Somoza and Weigel 2013). This regulation has been hypothesized to be 
489 important for flower maturation, but may also be involved in fruit dehiscence as ARF6 and 490 ARF8 are part of the gene regulatory network of fruit development (Zheng et al. 2019) (Figure 491 5). Another study found physical interaction of TCP4 and AS2 in yeast-two-hybrid experiments 492 (Li et al. 2012). AS2 has also previously been found to be involved in fruit patterning (Alonso493 Cantabrana et al. 2007) (Figure 5). Our analysis of ChIP-seq data on ChIP-Hub (Chen et al. 494 2019) additionally revealed that TCP4 binds to the promotor of YAB3 (Table 7), which has 495 been found to be differentially expressed between $L$. campestre and $L$. appelianum in all 496 structures examined. In flowers, TCP4 is expressed at a higher level in L. appelianum than in L. campestre while the expression pattern is the other way round for YAB3. Hence, it is conceivable that TCP4 represses YAB3 in flowers.

499

500

\section{Conclusions}

501 Taken together, our study provides insights into the gene regulatory differences in fruit

502 development between $L$. campestre producing dehiscent fruits and $L$. appelianum forming 503 indehiscent fruits. We confirm differences in the expression of the fruit development genes 504 SHP2 and FUL between the two species and reveal the importance of the valve identity gene YAB3 for fruit indehiscence in $L$. appelianum. We uncover the microRNA miR166 and the TCP transcription factors BRC1 and TCP4 as new candidates for causing the evolutionary transition from dehiscent to indehiscent fruits in L. appelianum.

\section{Methods}

\section{Plant material, RNA extraction and sequencing}

511 Seeds of Lepidium appelianum (KM 1754) were obtained from J Gaskin, USDA, Fremont 512 County, Wyoming, USA and seeds of L. campestre (KM 96) were aquired from the Botanical 513 Garden of the University of Zürich and subsequently mass propagated in the Botanical Garden 514 of Osnabrueck University, Germany. Seeds from these mass propagations were sawn on a 515 mixture of seedling substrate (Kammlott, Kammlott GmbH, Erfurt, Germany)/sand/vermiculite 516 (1-3 mm) (8:1:1) which was supplemented with $1 \mathrm{~g} \mathrm{~L}-1$ each of Osmocote mini 
517 (www.scotts.com,The Scotts Miracle-Gro Company, Marysville, OH, USA) and Triabon

518 (http://www.compo-expert.com, COMPO Expert GmbH, Münster, Germany). The seeds were 519 placed for 4 days at $4^{\circ} \mathrm{C}$ for stratification and then put in the greenhouse under a light-dark 520 cycle of 16 hours light, 8 hours dark of artificial light, plus daylight. After 5 weeks in the 521 greenhouse, the plants were vernalized for at least 13 weeks at $4^{\circ} \mathrm{C}$ with a light-dark cycle of 5228 hours light, 16 hours dark. After vernalization, the plants were put back in the greenhouse.

523 Plant material was harvested from two batches of independently grown plants 3 to 5 weeks 524 after the end of vernalization. Plant material was harvested between $12 \mathrm{pm}$ and $4 \mathrm{pm}$ to 525 minimize the effect of circadian rhythm. Late flower buds, flowers and early fruits were 526 harvested and immediately frozen in liquid nitrogen. Three samples were taken for each 527 species and each structure resulting in 18 samples in total. For each sample, about $100 \mathrm{mg}$ 528 plant material was pooled from four individual plants. The material was pulverized in liquid 529 nitrogen using a mortar and pestle. RNA was extracted using Qiazol (Qiagen) according to the 530 manufacturer's instructions. RNA quantity and quality was checked by gel electrophoresis. The 531 samples were sent to the Vienna BioCenter Facility for Next Generation Sequencing where 532 they were quality checked and sequenced on a HiSeqV4. For mRNA sequencing, 125bp 533 paired-end reads were produced and 50bp single-end reads were generated for small RNA 534 sequencing.

\section{Preprocessing of RNA-seq data}

536 Raw reads were corrected using Rcorrector (Song and Florea 2015) with default settings. 537 Uncorrectable reads were excluded using a python script obtained from 538 https://informatics.fas.harvard.edu/best-practices-for-de-novo-transcriptome-assembly-with-

539 trinity.html which was slightly modified for excluding uncorrectable reads from smallRNA 540 libraries. The remaining reads were trimmed with Trim Galore! 541 (https://www.bioinformatics.babraham.ac.uk/projects/trim galore/) using the following 542 settings: --clip_R1 12, --clip R2 12, --paired, --retain_unpaired, -543 phred33, --length 36, -q 5, --stringency 5, -e 0.1 for transcriptome reads 544 and the following settings --phred33, --length $18,--$ max_length $26,-\mathrm{q}$, -- 
stringency 5, -e $0.1,-a$ adapter for small RNA reads where adapter was replaced

546 by the corresponding adapter sequence identified using FastQC

547 (https://www.bioinformatics.babraham.ac.uk/projects/fastgc/). Thereafter, Poly-A and Poly-T

548 tails were removed from transcriptome reads with PrinSeq (Schmieder and Edwards 2011)

549 using the settings-trim_tail_left 5 and-trim_tail_right 5. Reads that mapped to

550 the genome of Frankliniella occidentalis (GenBank: GCF_000697945) or to rRNAs (GenBank:

551 X52320.1), mitochondrial (GenBank: Y08501.2) or chloroplast (GenBank: AP000423.1)

552 sequences from $A$. thaliana as determined using bowtie2 (settings: --very-sensitive-

553 local, --phred33) (Langmead and Salzberg 2012) were excluded from further analyses

554 from both, the transcriptome and the smallRNA libraries.

555 De novo assembly

556 To simplify de novo assembly, also duplicate reads, i.e. reads with the exact same length and 557 sequence, were removed. The remaining reads were assembled using Trinity (Grabherr et al. 558 2011b) with default settings for the two species L. campestre and L. appelianum separately. 559 To identify remaining contamination in the transcriptome, a BLASTn search was conducted 560 against the nucleotide sequence database of $\mathrm{NCBI}(\mathrm{nt})$ using the transcripts in the assembly 561 as query with the option -max_target_seqs 5. Transcripts for which the best BLASTn result 562 came from a non-plant species and had an eValue of $E<10^{-10}$ were removed from the 563 transcriptomes. The completeness of the assembled transcriptomes was evaluated using the 564 Benchmarking Universal Single-Copy Orthologs tool BUSCO (Simao et al. 2015) and their 565 accompanying dataset for eudicotyledons with 2121 groups (odb10).

\section{Separation of chimeras in the assemblies}

567 The initial assemblies contained chimeras composed from two different transcripts. As these 568 chimeras often result from misassembly (Yang and Smith 2013a), we sought to separate 569 chimeras into their separate transcripts. To recognize chimeras, we first conducted a BLASTn 570 search (Altschul et al. 1990) using the transcripts from the Lepidium transcriptomes as query 571 and the cDNA sequences of the representative $A$. thaliana gene model as provided by TAIR10 572 (TAIR10_cdna_20110103_representative_gene_model_updated.fasta) as database saving 
573 the best two subjects (i.e. A. thaliana cDNAs) for each query (i.e. each transcript from the

574 Lepidium transcriptomes) (Figure 8). Using a customized perl-script (Supplementary Data S1)

575 we searched for instances where the two subjects fitted to different regions of the query (i.e.

576 one part of the Lepidium transcript has a BLAST hit corresponding to one $A$. thaliana cDNA

577 while another part of the same transcript has a BLAST hit corresponding to another $A$. thaliana

578 cDNA). These instances likely indicate chimeric Lepidium transcripts. To identify the best

579 position to split the chimeras, we considered at which position and to what extend the $A$.

580 thaliana cDNAs matched to the Lepidium transcripts as shown in Figure 8. Chimeras were split

581 if the overlap was less than 150 nucleotides either in the middle of the overlap or at the 582 positions corresponding to the corrected end and beginning of the involved transcripts (Figure 583 8).

\section{Overlap between BLAST hits}

\section{Transcript of \\ L. species \\ Best two BLAST hits in A. thaliana cDNAs \\ Split position \\ Separated transcripts of $L$ species}

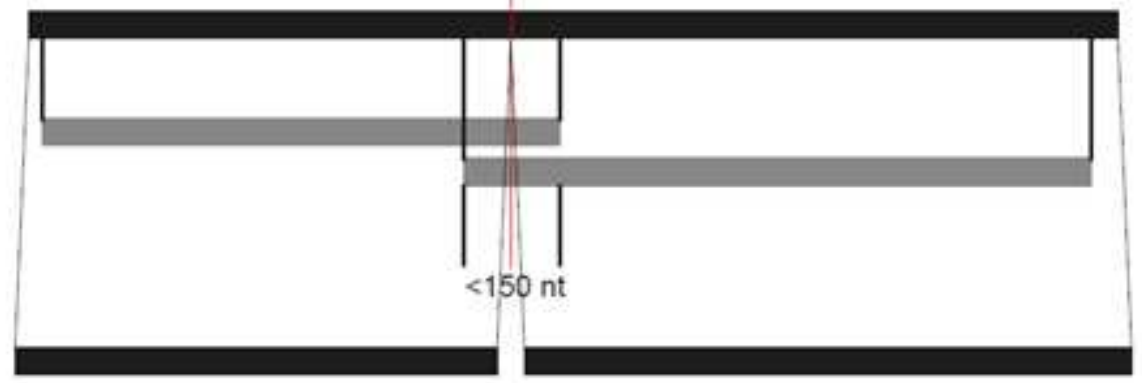

No overlap between BLAST hits
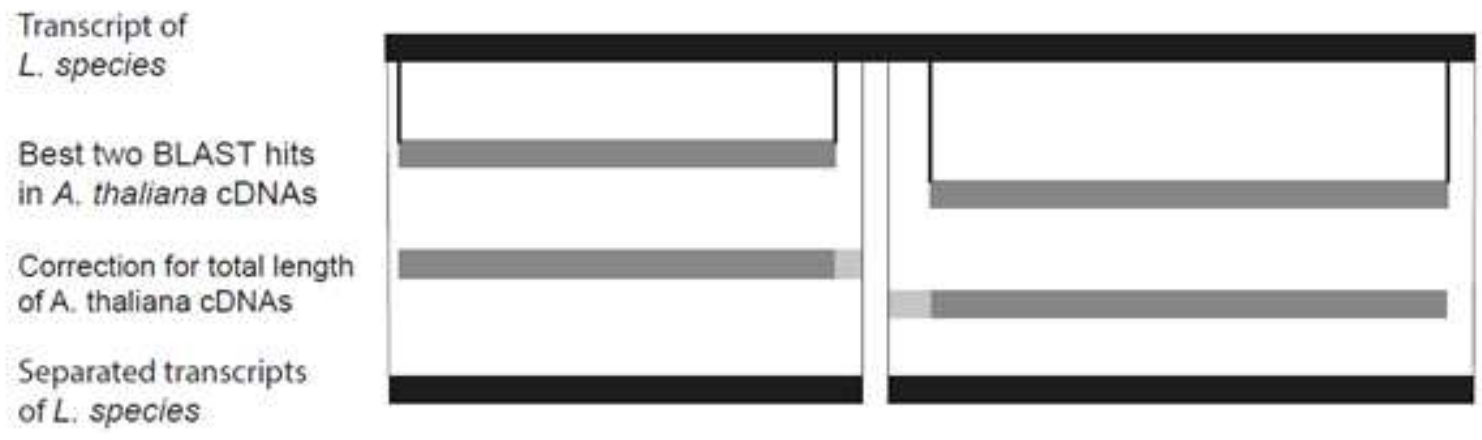

Figure 8: Schematic presentation of the detection and separation of chimeric transcripts in the

Lepidium transcriptomes. The procedure is slightly different depending on whether the positions of the best two BLAST hits in A. thaliana cDNAs overlap on the Lepidium transcript or not. If the positions of the best two BLAST hits overlap by less than 150 nucleotides, the Lepidium transcript is split in the 
589

590

591

592

593

594

595

596

597

598

599

600

601

602

603

604

605

606

607

608

609

610

611

612

613

614

615

616

middle of the overlap. Otherwise, the beginning and end of the involved transcripts was determined based on the total length of the fitting $A$. thaliana cDNAs.

\section{Identification of miRNAs in smallRNA libraries}

SmallRNA reads were mapped to mature miRNAs from Arabidopsis thaliana as downloaded from miRBase (Kozomara et al. 2019b) employing bowtie2 with the settings $-\mathrm{N} 1,-\mathrm{L} 18$. If a read mapped to a specific miRNA from $A$. thaliana this miRNA was considered to be present in the corresponding Lepidium species. Mature miRNAs only differing by one nucleotide were combined to avoid multiple mapping during read-counting. To identify novel miRNAs in Lepidium, we used ShortStack (Johnson et al. 2016) with the parameters -foldsize 500 , --dicermin 18 and the trinity transcriptome assembly of the corresponding Lepidium species as reference "genome". For L. campestre, ShortStack was run a second time, this time using the genome sequence of $L$. campestre as available at the National Centre for Biotechnology Information (Sayers et al. 2020) as reference. The stem-loop sequences classified as "N15" or "Y" by ShortStack were used as query sequences for BLAST searches of pre-miRNAs of $A$. thaliana as downloaded from miRBase (Kozomara et al. 2019b) to distinguish known from novel miRNAs. The stem-loop sequences classified as " $Y$ " by ShortStack without similarity to pre-miRNAs of $A$. thaliana were classified as novel Lepidium miRNAs.

\section{Determination of orthologs}

For transcriptome data, putative ortholog pairs were determined using the reciprocal best hit approach as follows. BLASTn searches were conducted using the transcriptome assembly with chimeras separated of $L$. campestre as query and the transcriptome assembly with chimeras separated of $L$. appelianum as subject and vice versa. For each transcript of $L$. campestre the best BLAST hits (having the same eValue, score and alignment length) in $L$. appelianum were recorded and vice versa. If a transcript $T_{c}$ from $L$. campestre had the transcript $T_{a}$ from $L$. appelianum among its best BLAST hits and transcript $T_{a}$ from $L$. appelianum had transcript $T_{c}$ from $L$. campestre in its list of best BLAST hits, these were 
617 considered as best reciprocal BLAST hit. Best reciprocal BLAST hits with an alignment length 618 of more than 250 nucleotides and where the length of the shorter sequence was at least $50 \%$ 619 of that of the longer sequence were considered as putative ortholog pairs. Additionally, another 620 BLASTn search was conducted using the transcripts in the transcriptomes as query and the 621 Arabidopsis thaliana TAIR10 cDNA dataset as database. The set of putative orthologous 622 transcript pairs was pruned such that only one transcript isoform was kept for each species 623 unless different isoforms fitted to different $A$. thaliana genes. The isoform with the longest 624 alignment length between the two species was chosen to be kept. This way, for each transcript 625 in the one transcriptome exactly one transcript in the other transcriptome was kept. We refer 626 to this dataset as the ortholog-transcriptome. The transcripts in the ortholog-transcriptome dataset were named using the TAIR10 identifier of the best BLAST result or numbered if no BLAST result was obtained this way.

629 For the miRNA data, orthologous miRNAs of the two Lepidium species were defined as those 630 miRNAs fitting to the same miRNA from $A$. thaliana. Comparison of the novel Lepidium 631 miRNAs revealed that none of these was found in both species.

\section{Read mapping and feature counting}

633 Preprocessed transcriptome and small RNA reads were mapped against ortholog634 transcriptome and mature miRNAs, respectively, using bowtie2 (settings: --verysensitive-local, --phred33 and settings: --phred33, -N 1, -L 18, respectively)

636 (Langmead and Salzberg 2012). A custom GFF was generated with one feature for each 637 transcript and miRNA. Mapped reads per feature were then counted using HTSeq-count 638 (Anders et al. 2015a) with the settings $-s$ no $-t$ transcript $-m$ union.

639 Differential gene expression analysis pipeline

640 Differentially expressed genes were identified using R (https://www.r-project.org/) and the 641 Bioconductor packages edgeR (Robinson et al. 2010b) and DESeq2 (Love et al. 2014b). 642 Transcript counts were normalized with respect to transcript length. Lowly expressed 643 transcripts with normalized counts and lowly expressed miRNAs with raw counts of less than 64419 were discarded. Considering the two species $L$. campestre and $L$ appelianum and the 
645 structures bud, flower and fruit, the following multi-factor design was used: species + 646 structure + species:structure. A Likelihood Ratio Test (LRT) and a quasi-likelihood

647 F-test were conducted in DESeq2 (command: DESeq (object, test="LRT", 648 reduced= species + structure)) and EdgeR (command: glmQLFit(object, 649 design)), respectively to identify differentially expressed and differently differentially 650 expressed genes. Only transcripts and miRNAs having a log-fold change to the base of 2 of 651 more than 1 were considered. For DESeq2 the false discovery rate threshold $\alpha$ was set to .001 . 652 For principal component analysis, count data was normalized using regularized logarithm 653 with the option blind=FALSE in DESeq2 and the principal components were plotted using 654 the plotPCA function in R.

\section{GO enrichment analysis}

656 Gene Ontology (GO) enrichment analysis was conducted on the GO website 657 (http://geneontology.org/) using the PANTHER Overrepresentation Test (Mi et al. 2019). The 658 TAIR10 identifiers of the transcripts in the ortholog-transcriptome were provided as reference 659 list. The TAIR10 identifiers of the transcripts which were identified as significantly differently expressed genes by both programs, DESeq2 and EdgeR, were provided as analyzed list. Arabidopsis thaliana was chosen as organism and "GO Molecular function complete" was selected as annotation data set. Enriched GO categories were determined using the Fisher's

663 Exact Test with False Discovery Rate correction.

664 GO categories and terms were also determined using the AnnotationDbi in R. Transcripts 665 associated with the term "DNA-binding transcription factor activity" were analyzed further.

\section{Promoter analyses}

667 Binding of transcription factors to the promotors of genes involved in fruit opening was 668 analysed using ChIP-Hub (http://www.chip-hub.org/). ChIP-Hub provides access to data on

669 binding sites determined using chromatin immunoprecipitation followed by sequencing (ChIP670 seq). On the ChIP-Hub website, $A$. thaliana was chosen as species and binding data was 671 visualized on the WashU EpiGenome Browser. For each fruit development gene, 1,500 
672 nucleotides upstream of the translation start codon were investigated and each occurance of

673 binding of one of the transcription factors found to be differentially regulated was noted.

674

675 List of abbreviations

676 AGL104: AGAMOUS-LIKE 104

677 ALC: ALCATRAZ

678 AP2: APETALA2

679 ARF: auxin-response factor

680 AS1: ASYMMETRIC LEAVES 1

681 AS2: ASYMMETRIC LEAVES 2

682 bHLH: basic helix-loop-helix

683 BP: BREVIPEDICELLUS

684 BRC1: BRANCHED1

685 BUSCO: Benchmarking of Universal Single-Copy Orthologs

686 ChIP-seq: chromatin immunoprecipitation followed by sequencing

687 DDEG: differently differentially expressed gene

688 DEG: differentially expressed gene

689 DZ: dehiscence zone

690 FIL: FILAMENTOUS FLOWER

691 FLC: FLOWERING LOCUS C

692 FUL: FRUITFULL

693 GO: gene ontology

694 IND: INDEHISCENT

695 JAG: JAGGED

696 LRT: Likelihood Ratio Test

697 MSG2: MASSUGU 2

698 MYB57: MYB DOMAIN PROTEIN 57

699 NF-YB2: NUCLEAR FACTOR Y-B2 
700 NF-YB10: NUCLEAR FACTOR Y-B10

701 nt: nucleotide sequence database of NCBI

702 NTT: NO TRANSMITTING TRACT

703 NZZ: NOZZLE

704 OBP4: OBF BINDING PROTEIN 4

705 PHB: PHABULOSA

706 PIF1: PHY-INTERACTING FACTOR 1

707 RPL: REPLUMLESS

708 RVE6: REVEILLE 6

709 SHP1: SHATTERPROOF1

710 SHP2: SHATTERPROOF2

711 SPL: SPOROCYTELESS

712 SPL4: SQUAMOSA PROMOTER BINDING PROTEIN-LIKE 4

713 SPT: SPATULA

714 TCP4: TCP FAMILY TRANSCRIPTION FACTOR 4

715 TF: transcription factor

716 TRY: TRIPTYCHON

717 WOX13: WUSCHEL-RELATED HOMEOBOX gene 13

718 YAB3: YABBY3

719 ORE1: ORESARA1

720 ZFP2: ZINC FINGER PROTEIN 2

721

722

Declarations

723

724 Ethics approval and consent to participate

725 Not applicable

726 Consent for publication

$727 \quad$ Not applicable 


\section{Availability of data and materials}

729 The datasets supporting the conclusions of this article are available at NCBI under the

730 BioProject identifier PRJNA769250 https://www.ncbi.nlm.nih.gov/bioproject/769250.

\section{$731 \quad$ Competing interests}

732 The authors declare that they have no competing interests.

\section{$733 \quad$ Funding}

734 Part of this work was supported by a grant from the Deutsche Forschungsgemeinschaft to 735 G.T. (TH 417/6-2).

\section{Authors' contributions}

737 GT conceived the project. LG and GT designed the experiments. KK performed the experiments. LG, NFP and MH analyzed the transcriptome data. LG, GT, MM and SR wrote the manuscript. All authors read and approved the final manuscript.

\section{Acknowledgements}

741 We thank Klaus Mummenhoff for seeds of $L$. appelianum and $L$. campestre. We are grateful 742 to Heidi Küster for skillful technical assistance as well as Tobias Horst Rogalla and Georgia 743 Daraki for preliminary analyses.

\section{References}

746 Adamczyk BJ, Fernandez DE (2009) MIKC* MADS domain heterodimers are required for pollen maturation and tube growth in Arabidopsis. Plant Physiol 149 (4):1713-1723. doi:10.1104/pp.109.135806

Aguilar-Martínez JA, Poza-Carrión C, Cubas P (2007) Arabidopsis BRANCHED1 acts as an integrator of branching signals within axillary buds. The Plant Cell 19 (2):458-472

Al-Shehbaz I, Mummenhoff K (2011) Stubendorffia and Winklera belong to the expanded Lepidium (Brassicaceae). Edinburgh Journal of Botany 68 (2):165 Common regulatory networks in leaf and fruit patterning revealed by mutations in the 
Altschul SF, Gish W, Miller W, Myers EW, Lipman DJ (1990) Basic local alignment search tool. J Mol Biol 215 (3):403-410. doi:10.1016/S0022-2836(05)80360-2

Anders S, Pyl PT, Huber W (2015a) HTSeq--a Python framework to work with highthroughput sequencing data. Bioinformatics 31 (2):166-169. doi:10.1093/bioinformatics/btu638

Anders S, Pyl PT, Huber W (2015b) HTSeq-a Python framework to work with highthroughput sequencing data. Bioinformatics 31 (2):166-169

Appel O, Al-Shehbaz I, Kubitzki K, Bayer C (2003) The families and genera of vascular plants. Cruciferae 5:75-174

Arteaga N, Savic M, Méndez-Vigo B, Fuster-Pons A, Torres-Pérez R, Oliveros JC, Picó FX, Alonso-Blanco C (2021) MYB Transcription Factors Drive Evolutionary Innovations in Arabidopsis Fruit Trichome Patterning. The Plant Cell

Ashburner M, Ball CA, Blake JA, Botstein D, Butler H, Cherry JM, Davis AP, Dolinski K, Dwight SS, Eppig JT, Harris MA, Hill DP, Issel-Tarver L, Kasarskis A, Lewis S, Matese JC, Richardson JE, Ringwald M, Rubin GM, Sherlock G (2000) Gene ontology: tool for the unification of biology. The Gene Ontology Consortium. Nat Genet 25 (1):25-29. doi:10.1038/75556

Axtell MJ (2013) ShortStack: comprehensive annotation and quantification of small RNA genes. Rna 19 (6):740-751

Balasubramanian S, Schneitz K (2000) NOZZLE regulates proximal-distal pattern formation, cell proliferation and early sporogenesis during ovule development in Arabidopsis thaliana. Development 127 (19):4227-4238

Ballester P, Ferrándiz C (2017) Shattering fruits: variations on a dehiscent theme. Current Opinion in Plant Biology 35:68-75

Bender RL, Fekete ML, Klinkenberg PM, Hampton M, Bauer B, Malecha M, Lindgren K, J AM, Perera MA, Nikolau BJ, Carter CJ (2013) PIN6 is required for nectary auxin response and short stamen development. Plant J 74 (6):893-904. doi:10.1111/tpj.12184 
Bhatt AM, Etchells JP, Canales C, Lagodienko A, Dickinson H (2004) VAAMANA-a BEL1like homeodomain protein, interacts with KNOX proteins BP and STM and regulates inflorescence stem growth in Arabidopsis. Gene 328:103-111

Braun N, de Saint Germain A, Pillot J-P, Boutet-Mercey S, Dalmais M, Antoniadi I, Li X, Maia-Grondard A, Le Signor C, Bouteiller N (2012) The pea TCP transcription factor PsBRC1 acts downstream of strigolactones to control shoot branching. Plant physiology 158 (1):225-238

Byrne ME, Groover AT, Fontana JR, Martienssen RA (2003) Phyllotactic pattern and stem cell fate are determined by the Arabidopsis homeobox gene BELLRINGER. Development 130 (17):3941-3950

Cai S, Lashbrook CC (2008) Stamen abscission zone transcriptome profiling reveals new candidates for abscission control: enhanced retention of floral organs in transgenic plants overexpressing Arabidopsis ZINC FINGER PROTEIN2. Plant Physiol 146 (3):1305-1321. doi:10.1104/pp.107.110908

Cao S, Kumimoto RW, Gnesutta N, Calogero AM, Mantovani R, Holt BF, 3rd (2014) A distal CCAAT/NUCLEAR FACTOR Y complex promotes chromatin looping at the FLOWERING LOCUS T promoter and regulates the timing of flowering in Arabidopsis. Plant Cell 26 (3):1009-1017. doi:10.1105/tpc.113.120352

Castillon A, Shen H, Huq E (2007) Phytochrome interacting factors: central players in phytochrome-mediated light signaling networks. Trends in plant science 12 (11):514521

Chanderbali AS, Yoo MJ, Zahn LM, Brockington SF, Wall PK, Gitzendanner MA, Albert VA, Leebens-Mack J, Altman NS, Ma H, dePamphilis CW, Soltis DE, Soltis PS (2010) Conservation and canalization of gene expression during angiosperm diversification accompany the origin and evolution of the flower. Proc Natl Acad Sci U S A 107 (52):22570-22575. doi:10.1073/pnas.1013395108

Chandler JO, Haas FB, Khan S, Bowden L, Ignatz M, Enfissi E, Gawthrop F, Griffiths A, Fraser PD, Rensing SA (2020) Rocket Science: The Effect of Spaceflight on 

$(4): 49$

814 Chen D, Fu L-Y, Zhang P, Chen M, Kaufmann K (2019) ChIP-Hub: an Integrative Platform for Exploring Plant Regulome. bioRxiv:768903

Cheng H, Song S, Xiao L, Soo HM, Cheng Z, Xie D, Peng J (2009) Gibberellin acts through jasmonate to control the expression of MYB21, MYB24, and MYB57 to promote stamen filament growth in Arabidopsis. PLoS Genet 5 (3):e1000440

Cole M, Nolte C, Werr W (2006) Nuclear import of the transcription factor SHOOT MERISTEMLESS depends on heterodimerization with BLH proteins expressed in discrete sub-domains of the shoot apical meristem of Arabidopsis thaliana. Nucleic Acids Research 34 (4):1281-1292

Dardick C, Callahan AM (2014) Evolution of the fruit endocarp: molecular mechanisms underlying adaptations in seed protection and dispersal strategies. Frontiers in plant science $5: 284$

Dinneny JR, Weigel D, Yanofsky MF (2005) A genetic framework for fruit patterning in Arabidopsis thaliana. Development 132 (21):4687-4696

Fernandez-Pozo N, Metz T, Chandler JO, Gramzow L, Mérai Z, Maumus F, Scheid OM, Theißen G, Schranz ME, Leubner-Metzger G (2021) Aethionema arabicum genome annotation using PacBio full-length transcripts provides a valuable resource for seed dormancy and Brassicaceae evolution research. The Plant Journal:-

Ferrandiz C, Liljegren SJ, Yanofsky MF (2000) Negative regulation of the SHATTERPROOF genes by FRUITFULL during Arabidopsis fruit development. Science 289 (5478):436438

Gao Z, Daneva A, Salanenka Y, Van Durme M, Huysmans M, Lin Z, De Winter F, Vanneste S, Karimi M, Van de Velde J, Vandepoele K, Van de Walle D, Dewettinck K, Lambrecht BN, Nowack MK (2018) KIRA1 and ORESARA1 terminate flower receptivity by promoting cell death in the stigma of Arabidopsis. Nat Plants 4 (6):365375. doi:10.1038/s41477-018-0160-7 
840 Gene Ontology Consortium T (2021) The Gene Ontology resource: enriching a GOld mine. Nucleic Acids Res 49 (D1):D325-d334. doi:10.1093/nar/gkaa1113

842 843

844

845

846

847

848

849

850

851

852

853

854

855

856

857

858

859

860

861

862

863

864

865

González-Reig S, Ripoll JJ, Vera A, Yanofsky MF, Martínez-Laborda A (2012) Antagonistic gene activities determine the formation of pattern elements along the mediolateral axis of the Arabidopsis fruit. PLoS Genet 8 (11):e1003020

González VL, Devine AM, Trizna M, Mulcahy DG, Barker KB, Coddington JA (2018) Open access genomic resources for terrestrial arthropods. Curr Opin Insect Sci 25:91-98. doi:10.1016/j.cois.2017.12.003

Grabherr MG, Haas BJ, Yassour M, Levin JZ, Thompson DA, Amit I, Adiconis X, Fan L, Raychowdhury R, Zeng Q (2011a) Trinity: reconstructing a full-length transcriptome without a genome from RNA-Seq data. Nature biotechnology 29 (7):644

Grabherr MG, Haas BJ, Yassour M, Levin JZ, Thompson DA, Amit I, Adiconis X, Fan L, Raychowdhury R, Zeng Q, Chen Z, Mauceli E, Hacohen N, Gnirke A, Rhind N, di Palma F, Birren BW, Nusbaum C, Lindblad-Toh K, Friedman N, Regev A (2011b) Full-length transcriptome assembly from RNA-Seq data without a reference genome. Nat Biotechnol 29 (7):644-652. doi:10.1038/nbt.1883

Groszmann M, Paicu T, Alvarez JP, Swain SM, Smyth DR (2011) SPATULA and ALCATRAZ, are partially redundant, functionally diverging bHLH genes required for Arabidopsis gynoecium and fruit development. The Plant Journal 68 (5):816-829

Gu Q, Ferrándiz C, Yanofsky MF, Martienssen R (1998) The FRUITFULL MADS-box gene mediates cell differentiation during Arabidopsis fruit development. Development 125 (8):1509-1517

Hall JC, Sytsma KJ, Iltis HH (2002) Phylogeny of Capparaceae and Brassicaceae based on chloroplast sequence data. American Journal of Botany 89 (11):1826-1842

Hsu PY, Devisetty UK, Harmer SL (2013) Accurate timekeeping is controlled by a cycling activator in Arabidopsis. Elife 2:e00473 
Huq E, Al-Sady B, Hudson M, Kim C, Apel K, Quail PH (2004) Phytochrome-interacting factor 1 is a critical bHLH regulator of chlorophyll biosynthesis. Science 305 (5692):1937-1941. doi:10.1126/science.1099728

Initiative TAG (2000) Analysis of the genome sequence of the flowering plant Arabidopsis thaliana. Nature 408 (6814):796-815. doi:10.1038/35048692

Johnson NR, Yeoh JM, Coruh C, Axtell MJ (2016) Improved Placement of Multi-mapping Small RNAs. G3 6 (7):2103-2111. doi:10.1534/g3.116.030452

Jung JH, Lee HJ, Ryu JY, Park CM (2016) SPL3/4/5 Integrate Developmental Aging and Photoperiodic Signals into the FT-FD Module in Arabidopsis Flowering. Mol Plant 9 (12):1647-1659. doi:10.1016/j.molp.2016.10.014

Kong Q, Singh SK, Mantyla JJ, Pattanaik S, Guo L, Yuan L, Benning C, Ma W (2020) Teosinte branched1/cycloidea/proliferating cell factor4 interacts with wrinkled1 to mediate seed oil biosynthesis. Plant Physiology 184 (2):658-665

Kozomara A, Birgaoanu M, Griffiths-Jones S (2019a) miRBase: from microRNA sequences to function. Nucleic acids research 47 (D1):D155-D162

Kozomara A, Birgaoanu M, Griffiths-Jones S (2019b) miRBase: from microRNA sequences to function. Nucleic Acids Res 47 (D1):D155-D162. doi:10.1093/nar/gky1141

Langmead B, Salzberg SL (2012) Fast gapped-read alignment with Bowtie 2. Nat Methods 9 (4):357-359. doi:10.1038/nmeth.1923

Lenser T, Tarkowská D, Novák O, Wilhelmsson PK, Bennett T, Rensing SA, Strnad M, Theißen G (2018) When the BRANCHED network bears fruit: how carpic dominance causes fruit dimorphism in Aethionema. The Plant Journal 94 (2):352-371

Li X, Lian H, Zhao Q, He Y (2019) MicroRNA166 monitors SPOROCYTELESS/NOZZLE for building of the anther internal boundary. Plant physiology 181 (1):208-220

Li Z, Li B, Shen WH, Huang H, Dong A (2012) TCP transcription factors interact with AS2 in the repression of class-I KNOX genes in Arabidopsis thaliana. The Plant Journal 71 (1):99-107 
893

894

895

896

897

898

899

900

901

902

903

904

905

906

907

908

909

910

911

912

913

914

915

916

917

918

919

920

Liljegren SJ, Ditta GS, Eshed Y, Savidge B, Bowman JL, Yanofsky MF (2000)

SHATTERPROOF MADS-box genes control seed dispersal in Arabidopsis. Nature 404 (6779):766-770

Liljegren SJ, Roeder AH, Kempin SA, Gremski K, Østergaard L, Guimil S, Reyes DK, Yanofsky MF (2004) Control of fruit patterning in Arabidopsis by INDEHISCENT. Cell 116 (6):843-853

Lorts CM, Briggeman T (2008) Evolution of fruit types and seed dispersal: a phylogenetic and ecological snapshot. Journal of systematics and evolution 46 (3):396-404

Love MI, Huber W, Anders S (2014a) Moderated estimation of fold change and dispersion for RNA-seq data with DESeq2. Genome biology 15 (12):1-21

Love MI, Huber W, Anders S (2014b) Moderated estimation of fold change and dispersion for RNA-seq data with DESeq2. Genome Biol 15 (12):550. doi:10.1186/s13059-0140550-8

Marsch-Martínez N, Zúñiga-Mayo VM, Herrera-Ubaldo H, Ouwerkerk PB, Pablo-Villa J, Lozano-Sotomayor P, Greco R, Ballester P, Balanzá V, Kuijt SJ, Meijer AH, Pereira A, Ferrándiz C, de Folter S (2014) The NTT transcription factor promotes replum development in Arabidopsis fruits. Plant J 80 (1):69-81. doi:10.1111/tpj.12617

Meakin PJ, Roberts JA (1990) Dehiscence of Fruit in Oilseed Rape (Brassica nap us L.) II. THE ROLE OF CELL WALL DEGRADING ENZYMES AND ETHYLENE. Journal of Experimental Botany 41 (8):1003-1011

Meakin PJ, Roberts JA (1991) Anatomical and biochemical changes associated with the induction of oilseed rape (Brassica napus) pod dehiscence by Dasineura brassicae (Winn.). Annals of Botany 67 (3):193-197

Mi H, Muruganujan A, Ebert D, Huang X, Thomas PD (2019) PANTHER version 14: more genomes, a new PANTHER GO-slim and improvements in enrichment analysis tools. Nucleic acids research 47 (D1):D419-D426

Michaels SD, Amasino RM (1999) FLOWERING LOCUS C encodes a novel MADS domain protein that acts as a repressor of flowering. The Plant Cell 11 (5):949-956 
Mitsuda N, Ohme-Takagi M (2008) NAC transcription factors NST1 and NST3 regulate pod shattering in a partially redundant manner by promoting secondary wall formation after the establishment of tissue identity. The Plant Journal 56 (5):768-778

Montes RAC, De Paoli E, Accerbi M, Rymarquis LA, Mahalingam G, Marsch-Martínez N, Meyers BC, Green PJ, de Folter S (2014) Sample sequencing of vascular plants demonstrates widespread conservation and divergence of microRNAs. Nature communications $5(1): 1-15$

Mühlhausen A, Lenser T, Mummenhoff K, Theißen G (2013) Evidence that an evolutionary transition from dehiscent to indehiscent fruits in $L$ epidium (B rassicaceae) was caused by a change in the control of valve margin identity genes. The Plant Journal $73(5): 824-835$

Nag A, King S, Jack T (2009) miR319a targeting of TCP4 is critical for petal growth and development in Arabidopsis. Proceedings of the National Academy of Sciences 106 (52):22534-22539

Ogawa M, Kay P, Wilson S, Swain SM (2009) ARABIDOPSIS DEHISCENCE ZONE POLYGALACTURONASE1 (ADPG1), ADPG2, and QUARTET2 are polygalacturonases required for cell separation during reproductive development in Arabidopsis. The Plant Cell 21 (1):216-233

Palatnik JF, Allen E, Wu X, Schommer C, Schwab R, Carrington JC, Weigel D (2003) Control of leaf morphogenesis by microRNAs. Nature 425 (6955):257-263

Rajani S, Sundaresan V (2001) The Arabidopsis myc/bHLH gene ALCATRAZ enables cell separation in fruit dehiscence. Current Biology 11 (24):1914-1922

Ramirez-Parra E, Perianez-Rodriguez J, Navarro-Neila S, Gude I, Moreno-Risueno MA, Del Pozo JC (2017) The transcription factor OBP 4 controls root growth and promotes callus formation. New Phytologist 213 (4):1787-1801

Reinhart BJ, Weinstein EG, Rhoades MW, Bartel B, Bartel DP (2002) MicroRNAs in plants. Genes \& development 16 (13):1616-1626 
948 Rhoades MW, Reinhart BJ, Lim LP, Burge CB, Bartel B, Bartel DP (2002) Prediction of plant microRNA targets. cell 110 (4):513-520

950

951

952

953

954

955

956

957

958

959

960

961

962

963

964

965

966

967

968

969

970

971

972

973

974

Ripoll JJ, Bailey LJ, Mai Q-A, Wu SL, Hon CT, Chapman EJ, Ditta GS, Estelle M, Yanofsky MF (2015) microRNA regulation of fruit growth. Nature plants 1 (4):1-9

Ripoll JJ, Roeder AH, Ditta GS, Yanofsky MF (2011) A novel role for the floral homeotic gene APETALA2 during Arabidopsis fruit development. Development 138 (23):5167-5176

Robinson MD, McCarthy DJ, Smyth GK (2010a) edgeR: a Bioconductor package for differential expression analysis of digital gene expression data. Bioinformatics 26 (1):139-140

Robinson MD, McCarthy DJ, Smyth GK (2010b) edgeR: a Bioconductor package for differential expression analysis of digital gene expression data. Bioinformatics 26 (1):139-140. doi:10.1093/bioinformatics/btp616

Roeder AH, Ferrándiz C, Yanofsky MF (2003) The role of the REPLUMLESS homeodomain protein in patterning the Arabidopsis fruit. Current biology 13 (18):1630-1635

Romera-Branchat M, Ripoll JJ, Yanofsky MF, Pelaz S (2013) The WOX 13 homeobox gene promotes replum formation in the Arabidopsis thaliana fruit. The Plant Journal 73 $(1): 37-49$

Rubio-Somoza I, Weigel D (2013) Coordination of flower maturation by a regulatory circuit of three microRNAs. PLoS Genet 9 (3):e1003374

Rymen B, Kawamura A, Schäfer S, Breuer C, Iwase A, Shibata M, Ikeda M, Mitsuda N, Koncz C, Ohme-Takagi M (2017) ABA suppresses root hair growth via the OBP4 transcriptional regulator. Plant Physiology 173 (3):1750-1762

Sayers EW, Beck J, Brister JR, Bolton EE, Canese K, Comeau DC, Funk K, Ketter A, Kim S, Kimchi A, Kitts PA, Kuznetsov A, Lathrop S, Lu Z, McGarvey K, Madden TL, Murphy TD, O'Leary N, Phan L, Schneider VA, Thibaud-Nissen F, Trawick BW, Pruitt KD, Ostell J (2020) Database resources of the National Center for Biotechnology Information. Nucleic Acids Res 48 (D1):D9-D16. doi:10.1093/nar/gkz899 
975 Schmieder R, Edwards R (2011) Quality control and preprocessing of metagenomic datasets. Bioinformatics 27 (6):863-864. doi:10.1093/bioinformatics/btr026

Schnittger A, Folkers U, Schwab B, Jürgens G, Hülskamp M (1999) Generation of a spacing pattern: the role of TRIPTYCHON in trichome patterning in Arabidopsis. The Plant Cell $11(6): 1105-1116$

Seale M, Bennett T, Leyser O (2017) BRC1 expression regulates bud activation potential but is not necessary or sufficient for bud growth inhibition in Arabidopsis. Development 144 (9):1661-1673

Simao FA, Waterhouse RM, loannidis P, Kriventseva EV, Zdobnov EM (2015) BUSCO: assessing genome assembly and annotation completeness with single-copy orthologs. Bioinformatics 31 (19):3210-3212. doi:10.1093/bioinformatics/btv351

Simão FA, Waterhouse RM, loannidis P, Kriventseva EV, Zdobnov EM (2015) BUSCO: assessing genome assembly and annotation completeness with single-copy orthologs. Bioinformatics 31 (19):3210-3212. doi:10.1093/bioinformatics/btv351

Smith HM, Hake S (2003) The interaction of two homeobox genes, BREVIPEDICELLUS and PENNYWISE, regulates internode patterning in the Arabidopsis inflorescence. The Plant Cell $15(8): 1717-1727$

Song L, Florea L (2015) Rcorrector: efficient and accurate error correction for Illumina RNAseq reads. GigaScience 4:48. doi:10.1186/s13742-015-0089-y

Spence J, Vercher Y, Gates P, Harris N (1996) 'Pod shatter'in Arabidopsis thalianaBrassica napus and B. juncea. Journal of Microscopy 181 (2):195-203

Tashiro S, Tian Ce, Watahiki MK, Yamamoto KT (2009) Changes in growth kinetics of stamen filaments cause inefficient pollination in massugu2, an auxin insensitive, dominant mutant of Arabidopsis thaliana. Physiologia plantarum 137 (2):175-187

Tatematsu K, Kumagai S, Muto H, Sato A, Watahiki MK, Harper RM, Liscum E, Yamamoto KT (2004) MASSUGU2 encodes Aux/IAA19, an auxin-regulated protein that functions together with the transcriptional activator NPH4/ARF7 to regulate differential growth 
responses of hypocotyl and formation of lateral roots in Arabidopsis thaliana. Plant Cell 16 (2):379-393. doi:10.1105/tpc.018630

1004

1005

1006

1007

1008

1009

1010

1011

1012

1013

1014

1015

1016

1017

1018

1019

1020

1021

1022

1023

1024

Wenkel S, Turck F, Singer K, Gissot L, Le Gourrierec J, Samach A, Coupland G (2006) CONSTANS and the CCAAT box binding complex share a functionally important domain and interact to regulate flowering of Arabidopsis. Plant Cell 18 (11):29712984. doi:10.1105/tpc.106.043299

Xu P, Chen H, Ying L, Cai W (2016) AtDOF5. 4/OBP4, a DOF transcription factor gene that negatively regulates cell cycle progression and cell expansion in Arabidopsis thaliana. Scientific reports $6(1): 1-13$

Yang Y, Smith SA (2013a) Optimizing de novo assembly of short-read RNA-seq data for phylogenomics. BMC Genomics 14:328. doi:10.1186/1471-2164-14-328

Yang Y, Smith SA (2013b) Optimizing de novo assembly of short-read RNA-seq data for phylogenomics. BMC genomics $14(1): 1-11$

Yao S, Liang F, Gill RA, Huang J, Cheng X, Liu Y, Tong C, Liu S (2020) A global survey of the transcriptome of allopolyploid Brassica napus based on single-molecule long-read isoform sequencing and Illumina-based RNA sequencing data. The Plant Journal 103 (2):843-857

Zheng L, Nagpal P, Villarino G, Trinidad B, Bird L, Huang Y, Reed JW (2019) miR167 limits anther growth to potentiate anther dehiscence. Development 146 (14)

\section{Tables}

Table 1: Number of reads obtained after sequencing and after correction and pruning steps.

\begin{tabular}{|c|c|c|c|c|c|c|}
\hline $\begin{array}{l}\text { Experi- } \\
\text { ment }\end{array}$ & $\begin{array}{l}\text { Spe- } \\
\text { cies }\end{array}$ & $\begin{array}{l}\text { Structu } \\
\text { re }\end{array}$ & $\begin{array}{l}\text { Repli- } \\
\text { cate }\end{array}$ & Raw reads & $\begin{array}{l}\text { Uncorrectable, } \\
\text { unpaired reads } \\
\text { removed }\end{array}$ & $\begin{array}{l}\text { Thrips and } \\
\text { organelle } \\
\text { sequences } \\
\text { removed }\end{array}$ \\
\hline \multirow{6}{*}{ 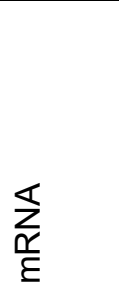 } & \multirow{6}{*}{ 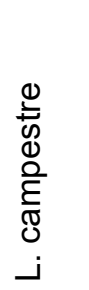 } & \multirow{3}{*}{ 믐 } & 1 & $56,364,306$ & $47,437,984$ & $42,661,682$ \\
\hline & & & 2 & $52,626,578$ & $44,103,956$ & $42,345,608$ \\
\hline & & & 3 & $46,984,896$ & $38,458,226$ & $35,556,348$ \\
\hline & & \multirow{3}{*}{$\begin{array}{l}\overline{0} \\
\frac{0}{0} \\
\frac{0}{4}\end{array}$} & 1 & $53,973,840$ & $45,071,412$ & $42,388,254$ \\
\hline & & & 2 & $54,176,184$ & $43,661,258$ & $40,639,670$ \\
\hline & & & 3 & $47,473,062$ & $37,866,352$ & $33,766,726$ \\
\hline
\end{tabular}




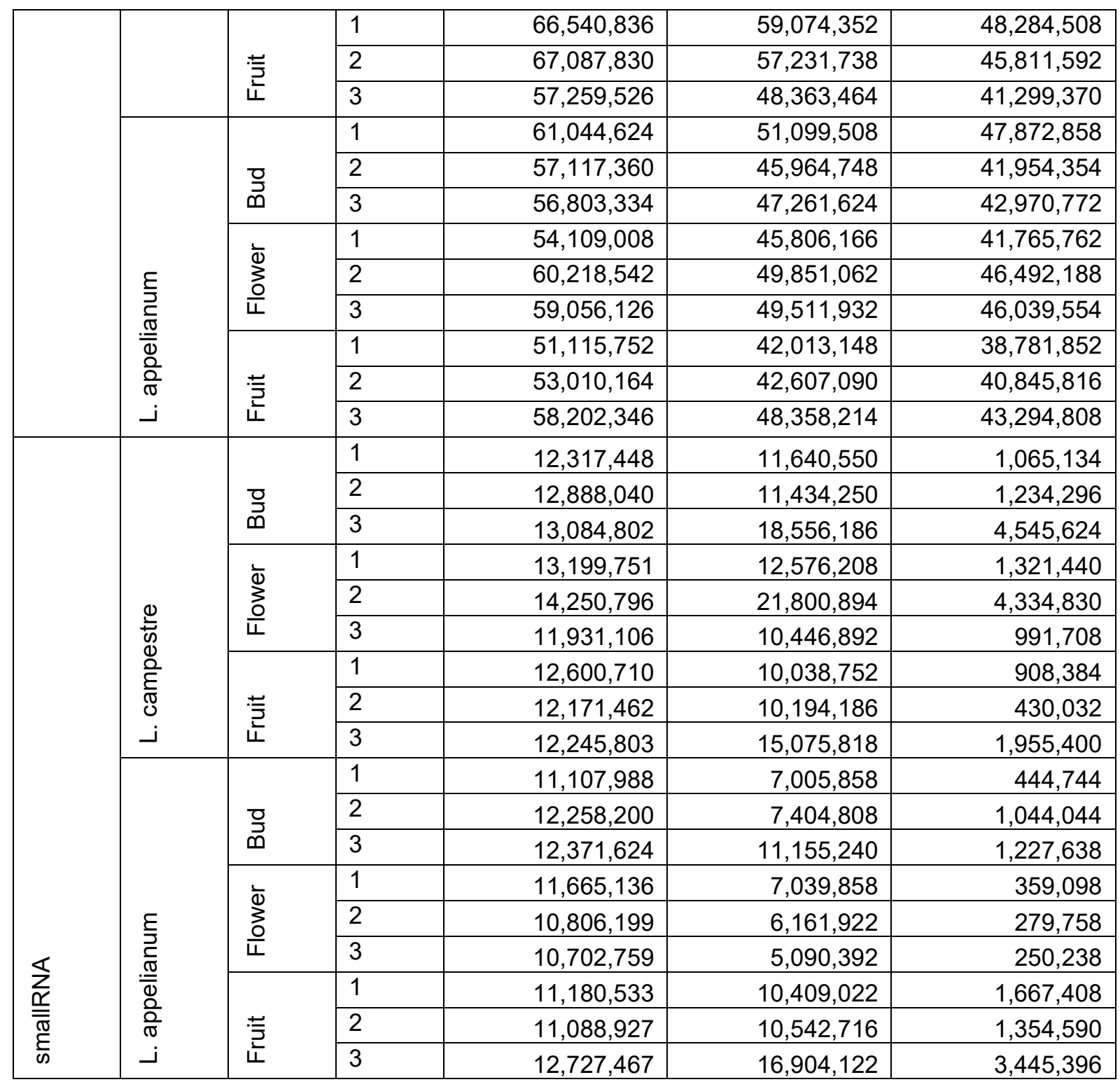

Table 2: Mature miRNAs identified in short read data of $L$. campestre and $L$. appelianum. conserved miRNAs according to Chavez-Montez et al., 2014

\begin{tabular}{|c|c|c|c|c|c|}
\hline miRNA family & $\begin{array}{l}\text { L. campestre } \\
\text { mature } \\
\text { miRNA }\end{array}$ & $\begin{array}{l}\text { ShortStack } \\
\text { genome }\end{array}$ & $\begin{array}{l}\text { ShortStack } \\
\text { transcriptom } \\
\text { e }\end{array}$ & $\begin{array}{l}L . \\
\text { appelianum } \\
\text { mature } \\
\text { miRNA }\end{array}$ & $\begin{array}{l}\text { ShortStack } \\
\text { transcripto } \\
\text { me }\end{array}$ \\
\hline miR156a-3p/miR156c-3p & $\mathrm{x}$ & miR156c & & $\mathrm{x}$ & miR156a \\
\hline $\begin{array}{l}\mathrm{miR} 156 \mathrm{a}-5 \mathrm{p} / \mathrm{miR} 156 \mathrm{~b}-5 \mathrm{p} / \\
\mathrm{miR} 156 \mathrm{c}-5 \mathrm{p} / \mathrm{miR} 156 \mathrm{~d}-5 \mathrm{p} / \\
\mathrm{miR} 156 \mathrm{e} / \mathrm{miR} 156 \mathrm{f}-5 \mathrm{p} / \\
\mathrm{miR} 156 \mathrm{~g} / \mathrm{miR} 156 \mathrm{~h} / \\
\mathrm{miR} 156 \mathrm{~m} / \mathrm{miR} 156 \mathrm{j}\end{array}$ & $x$ & $\begin{array}{l}\text { miR156e, } \\
\text { miR156b, } \\
\text { miR156c }\end{array}$ & & $x$ & $\begin{array}{l}\text { miR156a, } \\
\text { miR156j }\end{array}$ \\
\hline miR156b-3p & $x$ & miR156b & & $x$ & \\
\hline miR156d-3p & & & & $\mathrm{x}$ & \\
\hline miR157a-3p/miR157b-3p & $x$ & & & $\mathrm{x}$ & \\
\hline $\begin{array}{l}\mathrm{miR} 157 a-5 p / m i R 157 b-5 p / \\
\mathrm{miR} 157 c-5 p / m i R 157 d\end{array}$ & $x$ & & miR157c & $x$ & \\
\hline miR157c-3p & $\mathrm{x}$ & & miR157c & $x$ & \\
\hline
\end{tabular}




\begin{tabular}{|c|c|c|c|c|c|}
\hline miR158a-3p/miR158b & $x$ & & & $x$ & miR158a \\
\hline miR159a/miR159b-3p & $\mathrm{x}$ & & & $\mathrm{x}$ & \\
\hline miR159c & $x$ & & & $x$ & \\
\hline miR160a-3p & $x$ & miR160a & & $x$ & \\
\hline $\begin{array}{l}\text { miR160a-5p/miR160b/ } \\
\text { miR160c-5p }\end{array}$ & $x$ & $\begin{array}{l}\text { miR160a, } \\
\text { miR160c }\end{array}$ & miR160b & $x$ & \\
\hline miR160c-3p & $\mathrm{x}$ & miR160c & & & \\
\hline miR161.1 & $\mathrm{x}$ & & & & \\
\hline $\operatorname{miR} 161.2$ & $x$ & & & & \\
\hline$m i R 162 a-3 p / m i R 162 b-3 p$ & $x$ & miR162b & & $x$ & miR162b \\
\hline miR162a-5p/miR162b-5p & $\mathrm{x}$ & miR162b & & $x$ & miR162b \\
\hline $\begin{array}{l}\text { miR164a/miR164b-5p/ } \\
\text { miR164c-5p }\end{array}$ & $x$ & miR164a & & $\mathrm{x}$ & \\
\hline miR164b-3p & $\mathrm{x}$ & & & $\mathrm{x}$ & \\
\hline miR164c-3p & $\mathrm{x}$ & & & $x$ & \\
\hline $\begin{array}{l}\mathrm{miR} 165 \mathrm{a}-3 \mathrm{p} / \mathrm{miR} 165 \mathrm{~b} / \\
\mathrm{miR} 166 \mathrm{a}-3 \mathrm{p} / \mathrm{miR} 166 \mathrm{~b}-3 \mathrm{p} / \\
\mathrm{miR} 166 \mathrm{c} / \mathrm{miR} 166 \mathrm{~d} / \\
\mathrm{miR} 166 \mathrm{e}-3 \mathrm{p} / \mathrm{miR} 166 \mathrm{f} / \mathrm{miR} 166 \mathrm{~g}\end{array}$ & $\mathrm{x}$ & $\begin{array}{l}\text { miR165b, } \\
\text { miR166d, } \\
\text { miR166g }\end{array}$ & & $\mathrm{x}$ & $\begin{array}{l}\operatorname{miR} 166 a, \\
\operatorname{miR} 166 b, \\
\operatorname{miR} 166 e, \\
\operatorname{miR} 166 f\end{array}$ \\
\hline miR165a-5p & $x$ & & & $x$ & \\
\hline miR166a-5p/miR166b-5p & $\mathrm{x}$ & & & $\mathrm{x}$ & $\begin{array}{l}\text { miR166a, } \\
\text { miR166b }\end{array}$ \\
\hline miR166e-5p & $x$ & & & $x$ & miR166e \\
\hline miR167a-3p & $x$ & & & $x$ & \\
\hline miR167a-5p/miR167b/miR167d & $\mathrm{x}$ & miR167b & & $\mathrm{x}$ & \\
\hline miR167c-5p & $x$ & miR167c & & $x$ & \\
\hline miR168a-3p & $x$ & & miR168a & $x$ & miR168a \\
\hline miR168a-5p/miR168b-5p & $\mathrm{x}$ & & miR168a & $\mathrm{x}$ & miR168a \\
\hline $\begin{array}{l}\text { miR169a-5p/miR169b-5p/ } \\
\text { miR169c }\end{array}$ & $\mathrm{x}$ & & & $x$ & \\
\hline $\begin{array}{l}\mathrm{miR} 169 \mathrm{~d} / \mathrm{miR} 169 \mathrm{e} / \\
\mathrm{miR} 169 \mathrm{f}-5 \mathrm{p} / \mathrm{miR} 169 \mathrm{~g}-5 \mathrm{p}\end{array}$ & $x$ & & & $\mathrm{x}$ & \\
\hline miR169f-3p & $x$ & & & $x$ & \\
\hline miR170-5p/miR171a-5p & $x$ & miR171a & & $\mathrm{x}$ & $\begin{array}{l}\operatorname{miR} 170 \\
\operatorname{miR} 171 a\end{array}$ \\
\hline miR171a-3p & $x$ & $\operatorname{miR} 171 a$ & & $x$ & \\
\hline miR171b-5p/miR171c-5p & $x$ & & $\operatorname{miR} 171 b$ & $x$ & $\begin{array}{l}\operatorname{miR} 171 b \\
\operatorname{miR} 171 \mathrm{c}\end{array}$ \\
\hline miR171b-3p/miR171c-3p & $\mathrm{x}$ & & $\mathrm{miR} 171 \mathrm{~b}$ & $\mathrm{x}$ & $\begin{array}{l}\operatorname{miR} 171 b \\
\operatorname{miR} 171 \mathrm{c}\end{array}$ \\
\hline $\begin{array}{l}\mathrm{miR} 172 a / m i R 172 b-3 p / \\
\text { miR172c/miR172d-3p/ } \\
\text { miR172e-3p }\end{array}$ & $\mathrm{x}$ & $\begin{array}{l}\text { miR172b } \\
\text { (partial) }\end{array}$ & $\operatorname{miR} 172 \mathrm{e}$ & $\mathrm{x}$ & $\begin{array}{l}\text { miR172b } \\
\text { (partial) }\end{array}$ \\
\hline miR172b-5p/miR172e-5p & $x$ & $\begin{array}{l}\text { miR172b } \\
\text { (partial) }\end{array}$ & $\operatorname{miR} 172 \mathrm{e}$ & $\mathrm{x}$ & $\begin{array}{l}\text { miR172b } \\
\text { (partial) }\end{array}$ \\
\hline miR172d-5p & $x$ & & & $\mathrm{x}$ & \\
\hline miR2111b-3p & $\mathrm{x}$ & & & & \\
\hline miR319a/miR319b & $x$ & & & $x$ & \\
\hline miR319c & $x$ & & & $x$ & \\
\hline miR390a-3p & $\mathrm{x}$ & & & $\mathrm{x}$ & \\
\hline miR390a-5p/miR390b-5p & $x$ & & & $x$ & \\
\hline miR390b-3p & $x$ & & & $x$ & \\
\hline miR393a-3p/miR393b-3p & $\mathrm{x}$ & & miR393b & $\mathrm{x}$ & miR393b \\
\hline miR393a-5p/miR393b-5p & $\mathrm{x}$ & & miR393b & $x$ & miR393b \\
\hline miR394a/miR394b-5p & $\mathrm{x}$ & & & $\mathrm{x}$ & miR394b \\
\hline $\begin{array}{l}\text { miR395a/miR395b/miR395c/ } \\
\mathrm{miR395d} / \mathrm{miR395e/miR395f}\end{array}$ & $\mathrm{x}$ & & & $\mathrm{x}$ & $\begin{array}{l}\text { miR395d, } \\
\text { miR395f }\end{array}$ \\
\hline miR396a-3p & $x$ & miR396a & & $\mathrm{x}$ & \\
\hline miR396a-5p/miR396b-5p & $\mathrm{x}$ & miR396a & & $\mathrm{x}$ & \\
\hline miR396b-3p & $\mathrm{x}$ & & & $\mathrm{x}$ & \\
\hline $\begin{array}{l}\text { miR398a-3p/miR398b-3p/ } \\
\text { miR398c-3p }\end{array}$ & & & & $\mathrm{x}$ & miR398b \\
\hline miR399a/miR399b/miR399c-3p & $\mathrm{x}$ & miR399a & & $x$ & \\
\hline miR399f & & & & $\mathrm{x}$ & \\
\hline miR403-3p & $\mathrm{x}$ & & & $\mathrm{x}$ & \\
\hline miR403-5p & $x$ & & & & \\
\hline
\end{tabular}




\begin{tabular}{|c|c|c|c|}
\hline$m i R 408-3 p$ & $\mathrm{x}$ & & $x$ \\
\hline miR408-5p & $\mathrm{x}$ & & $x$ \\
\hline miR472 & & $\mathrm{miR} 472$ & \\
\hline miR8174 & & & $x$ \\
\hline $\operatorname{miR} 8175$ & $x$ & & $x$ \\
\hline miR824-3p & $x$ & & $\mathrm{x}$ \\
\hline miR824-5p & $x$ & & $x$ \\
\hline miR827 & $x$ & $\operatorname{miR} 827$ & $x$ \\
\hline miR845a & $x$ & & \\
\hline miR845b & $x$ & & \\
\hline $\mathrm{miR858a/miR858b}$ & $\mathrm{x}$ & & $\mathrm{x}$ \\
\hline miR863-5p & $x$ & & \\
\hline
\end{tabular}

1031 Table 3: Gene ontology (GO) terms significantly over- or underrepresented in DEGs and

1032 DDEGs. Terms of the category molecular function of GO were analysed.

\begin{tabular}{|l|l|l|l|}
\hline Dataset & GO term & $\begin{array}{l}\text { Fold } \\
\text { enrichment }\end{array}$ & FDR \\
\hline La vs. Lc bud & protein binding (GO:0005515) & 0.74 & $3.43 \mathrm{E}-02$ \\
\hline & $\begin{array}{l}\text { transferase activity, transferring phosphorus-containing } \\
\text { groups (GO:0016772) }\end{array}$ & 0.44 & $2.84 \mathrm{E}-02$ \\
\hline La vs. Lc flower & none & & \\
\hline La vs. Lc fruit & none & & \\
\hline Lc flower vs. bud & pectinesterase activity (GO:0030599) & 10.69 & $1.48 \mathrm{E}-02$ \\
\hline & RNA binding (GO:0003723) & 0.15 & $8.99 \mathrm{E}-03$ \\
\hline La flower vs. bud & sodium:proton antiporter activity (GO:0015385) & 14.17 & $2.35 \mathrm{E}-04$ \\
\hline & cellulose synthase (UDP-forming) activity (GO:0016760) & 10.52 & $3.18 \mathrm{E}-02$ \\
\hline & polygalacturonase activity (GO:0004650) & 8.13 & $8.50 \mathrm{E}-03$ \\
\hline & iron ion binding (GO:0005506) & 3.12 & $3.48 \mathrm{E}-02$ \\
\hline & $\begin{array}{l}\text { oxidoreductase activity acting on paired donors with } \\
\text { incorporation or reduction of molecular oxygen } \\
\text { (GO:0016705) }\end{array}$ & 2.89 & $4.07 \mathrm{E}-02$ \\
\hline protein binding (GO:0005515) & 0.71 & $3.99 \mathrm{E}-02$ \\
\hline RNA binding (GO:0003723) & 0.17 & $1.30 \mathrm{E}-03$ \\
\hline Lc fruit vs. flower & heme binding (GO:0020037) & 5.11 & $9.54 \mathrm{E}-04$ \\
\hline & $\begin{array}{l}\text { hydrolase activity, hydrolyzing O-glycosyl compounds } \\
\text { (GO:0004553) }\end{array}$ & 4.28 & $1.15 \mathrm{E}-03$ \\
\hline na fruit vs. flower & none & & \\
\hline flower vs. bud & acid-amino acid ligase activity (GO:0016881) & 40.35 & $1.53 \mathrm{E}-02$ \\
\hline fruit vs. flower & none & \\
\hline
\end{tabular}


Table 4: Differentially expressed genes in different structures annotated as "DNA-binding transcription factor activity" (GO:0003700).

\begin{tabular}{|c|c|c|c|c|c|}
\hline & Ortholog ID & Ortholog name & Ortholog description (based on TAIR) & $\begin{array}{l}\text { Reg. } \\
\text { L.c. }\end{array}$ & $\begin{array}{l}\text { Reg. } \\
\text { L.a. }\end{array}$ \\
\hline \multirow{13}{*}{ 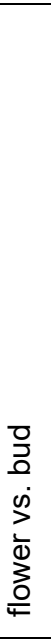 } & AT1G22130.1 & AGL104 & Pollen development and pollen tube growth & $-3,0$ & $-3,6$ \\
\hline & AT1G61110.1 & anac025, NAC025 & Endosperm cell expansion during germination & $-3,6$ & $-3,2$ \\
\hline & AT1G69490.1 & ANAC029, ATNAP, NAP & Leaf senescence (Guo and Gan, 2006), drought stress response (Sakuraba et al., 2015) & 3,4 & 2,8 \\
\hline & AT2G47190.1 & ATMYB2, MYB2 & $\begin{array}{l}\text { Salt tolerance, Phosphate Starvation Response (Baek et al., 2013), Abscisic Acid Signaling (Abe et al., } \\
\text { 2003), Plant Senescence (Guo and Gan, 2011) }\end{array}$ & 3,7 & 2,6 \\
\hline & AT3G04070.1 & anac047, NAC047 & Flood induced leaf movement (Rauf et al, 2013) & 3,3 & 3,8 \\
\hline & AT3G23050.1 & AXR2, IAA7 & Auxin response (Timpte et al., 1994), shoot and root gravitopism (Timpte et al., 1992) & 2,0 & 3,1 \\
\hline & AT3G58120.1 & ATBZIP61, BZIP61 & n.a. & $-3,7$ & $-2,5$ \\
\hline & AT4G10240.1 & bbx23 & $\begin{array}{l}\text { Temperature-induced hypocotyl elongation together with BBX18 (Ding et al. 2018), } \\
\text { photomorphogenesis activated by PIF1 and PIF3 (Zhang et al., 2017) }\end{array}$ & $-4,8$ & $-6,3$ \\
\hline & AT4G27330.1 & NZZ, SPL & $\begin{array}{l}\text { Initiation of micro- and megagametogenesis, patterning of the ovule, differentiation of primary } \\
\text { sporogenous cells into microsporocytes, regulation of anther cell differentiation }\end{array}$ & $-7,9$ & $-8,7$ \\
\hline & AT4G28500.1 & ANAC073, NAC073, SND2 & Secondary cell wall development (Hussey et al., 2011), phloem development (Kim et al., 2020) & $-2,8$ & $-2,9$ \\
\hline & AT5G13180.1 & ANAC083, NAC083, VNI2 & Xylem vessel formation, leaf senescence (Yang et al., 2011) & 2,7 & 3,5 \\
\hline & AT5G39610.1 & $\begin{array}{l}\text { ANAC092, ATNAC2, ATNAC6, } \\
\text { NAC2, NAC6, ORE1 }\end{array}$ & Leaf senescence (Kim et al., 2018), Termination of flower receptivity (Gao et al., 2018) & 4,0 & 3,5 \\
\hline & AT5G57520.1 & ATZFP2, ZFP2 & Abscission of floral organs (Cai and Lashbrook, 2008) & 2,1 & 3,4 \\
\hline \multirow{5}{*}{ 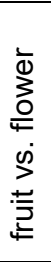 } & AT2G01940.3 & ATIDD15, SGR5 & Auxin biosynthesis and transport, aerial organ morphogenesis and gravitropic responses & $-3,3$ & $-4,2$ \\
\hline & AT2G20180.2 & PIF1, PIL5 & Negative regulation of phytochrome-mediated seed germination & $-2,5$ & $-5,2$ \\
\hline & AT3G23050.1 & AXR2, IAA7 & Auxin response (Timpte et al., 1994), shoot and root gravitopism (Timpte et al., 1992) & $-2,3$ & $-3,2$ \\
\hline & AT5G64530.1 & ANAC104, XND1 & $\begin{array}{l}\text { Xylem formation (Tang et al., 2018, Zhao et al., 2017), Regulation of secondary wall synthesis (Zhao et } \\
\text { al., 2007) }\end{array}$ & $-3,6$ & $-5,1$ \\
\hline & AT5G67300.1 & $\begin{array}{l}\text { ATMYB44, ATMYBR1, } \\
\text { MYB44, MYBR1 }\end{array}$ & Abscisic acid signaling, abiotic stress tolerance & $-2,3$ & $-3,9$ \\
\hline
\end{tabular}


Table 5: DEGs between the two Lepidium species annotated as "DNA-binding transcription factor activity". (G0:0003700)

\begin{tabular}{|c|c|c|c|c|c|}
\hline Ortholog ID & Ortholog name & Ortholog description (based on TAIR) & $\begin{array}{l}\text { Reg. } \\
\text { bud }\end{array}$ & $\begin{array}{l}\text { Reg. } \\
\text { flower }\end{array}$ & $\begin{array}{l}\text { Reg. } \\
\text { fruit }\end{array}$ \\
\hline AT1G01060.1 & LHY & Involved in circadian rhythm & 2.5 & 2.4 & 2.8 \\
\hline AT1G14687.1 & HB32, ZHD14 & n.a. & -4.0 & -3.1 & -2.2 \\
\hline AT1G27370.1 & SPL10 & Development of lateral organs, lamina shape, lateral root growth (Yu et al., 2015) & -3.9 & -3.8 & -4.6 \\
\hline AT1G46264.1 & HSFB4, SCZ & Asymmetry of stem cell devisions & -5.3 & -4.4 & -4.1 \\
\hline AT1G53160.2 & FTM6, SPL4 & Regulation of flowering and vegetative phase change & -5.2 & -5.3 & -4.5 \\
\hline AT1G79840.2 & GL2 & Regulation of epidermal cell identity, regulation of seed oil content & 3.5 & 3.6 & 2.7 \\
\hline AT3G09370.2 & MYB3R-3 & DNA damage response & -2.4 & -2.2 & -2.6 \\
\hline AT3G11280.1 & n.a. & n.a. & -2.6 & -2.9 & -2.9 \\
\hline AT3G14020.1 & NF-YA6 & Involved in male gametogenesis, embryogenesis, and seed development (Mu et al, 2012) & -2.6 & -2.2 & -2.4 \\
\hline AT3G53340.1 & NF-YB10 & Flowering time determination (Tao et al., 2017) & 3.3 & 3.4 & 4.9 \\
\hline AT4G00180.1 & YAB3 & Specification of abaxial cell fate, involved in fruit patterning along with FIL & -2.6 & -2.5 & -2.5 \\
\hline AT4G01280.2 & RVE5 & Clock regulation, growth regulation (Gray et al., 2017) & 2.6 & 2.2 & 2.2 \\
\hline AT4G31060.1 & n.a. & n.a. & -2.9 & -3.5 & -3.4 \\
\hline AT5G04340.1 & $\begin{array}{l}\text { C2H2, CZF2, } \\
\text { ZAT6 }\end{array}$ & Phosphate homeostasis (Devaiah et al., 2007), Cd accumulation and tolerance (Chen et al. 2016) & 4.0 & 4.6 & 3.4 \\
\hline AT5G10140.1 & $\begin{array}{l}\text { AGL25, FLC, } \\
\text { FLF, RSB6 }\end{array}$ & Flowering time determination & 3.7 & 4.1 & 5.6 \\
\hline AT5G39760.1 & HB23, ZHD10 & Light-induced developmenet (Perrella et al., 2018) & 7.2 & 6.3 & 4.9 \\
\hline AT5G41920.1 & SCL23 & Endodermis development (Yoon et al., 2016; Cui et al., 2014) & -5.0 & -5.3 & -3.9 \\
\hline AT5G47640.1 & NF-YB2 & Flowering time determination (Hou et al., 2014) & 2.2 & 2.6 & 2.4 \\
\hline AT5G60910.1 & AGL8, FUL & Fruit development (Gu et al, 1998), apical hook development (Führer et al., 2020) & -2.9 & -2.4 & -2.7 \\
\hline
\end{tabular}


Table 6: DDEGs in different structures annotated as "DNA-binding transcription factor activity" (G0:0003700)

\begin{tabular}{|c|c|c|c|c|}
\hline & Ortholog ID & Ortholog name & Ortholog description (based on TAIR) & Reg. \\
\hline \multirow{2}{*}{ 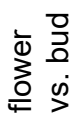 } & AT3G15540.1 & IAA19, MSG2 & Stamen filaments development & 4,8 \\
\hline & AT5G47230.1 & AtMACD1, ERF102, ERF5 & Stress response, leaf growth & 5,3 \\
\hline \multirow{7}{*}{ 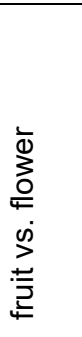 } & AT2G20180.2 & PIF1, PIL5 & Phytochrome-mediated seed germination & 2,7 \\
\hline & AT3G01530.1 & ATMYB57, MYB57 & Stamen and nectary development (Bender et al., 2013) & $-2,9$ \\
\hline & AT3G15030.1 & MEE35, TCP4 & $\begin{array}{l}\text { Cotyledon, leaf and petal development, seed oil accumulation } \\
\text { Overexpression of TCP4 causes increased deposition of lignin and cellulose (Sun et al., 2017), TCP4 interacts } \\
\text { with AS2 to regulate BP? (Li et al., 2012) }\end{array}$ & $-4,3$ \\
\hline & AT3G18550.1 & BRC1, TCP18 & Arrests axillary bud development and prevents axillary bud outgrowth. Role in flowering control. & $-4,3$ \\
\hline & AT5G52660.2 & RVE6 & Involved in circadian rhythm & $-2,6$ \\
\hline & AT5G53200.1 & TRY & Trichome and root hair patterning, phosphate starvation response & $-6,0$ \\
\hline & AT5G60850.1 & DOF5.4, OBP4 & Cell Cycle Progression and Cell Expansion & $-2,3$ \\
\hline
\end{tabular}


Table 7: Binding of TFs found to be DDEGs to the promotors of known fruit development genes.

\begin{tabular}{|c|c|c|c|c|c|c|}
\hline & & PIF1 & MYB57 & TCP4 & RVE6 & OBP4 \\
\hline \multirow{8}{*}{ 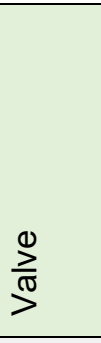 } & AS1 & 1 & 1 & - & - & 3 \\
\hline & AS2 & - & 1 & - & - & 1 \\
\hline & JAG & 2 & - & - & - & 1 \\
\hline & FIL & 1 & - & - & 3 & 2 \\
\hline & YAB3 & - & - & 1 & 2 & 1 \\
\hline & ARF6 & 1 & - & - & 2 & 1 \\
\hline & ARF8 & - & - & - & - & - \\
\hline & FUL & - & 1 & - & 1 & 1 \\
\hline \multirow{5}{*}{$\frac{\frac{\xi}{\partial}}{\frac{0}{0}}$} & AP2 & - & 1 & - & - & 2 \\
\hline & NTT & - & 1 & - & 1 & 3 \\
\hline & $\mathrm{BP}$ & - & - & - & 1 & 2 \\
\hline & WOX13 & - & - & - & - & 4 \\
\hline & RPL & - & - & - & 3 & 1 \\
\hline \multirow{5}{*}{ 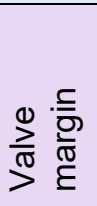 } & SHP1 & - & - & - & 2 & 5 \\
\hline & SHP2 & - & 1 & - & 1 & 5 \\
\hline & IND & - & - & - & 2 & 3 \\
\hline & ALC & - & 1 & 1 & 2 & 2 \\
\hline & SPT & 1 & - & - & 1 & 2 \\
\hline
\end{tabular}

